University of Rhode Island

DigitalCommons@URI

Open Access Dissertations

1982

\title{
Children's Fears: The Development of a New Measure and Preliminary Findings Regarding Age and Sex Differences
}

Michael Hayden Davies

University of Rhode Island

Follow this and additional works at: https://digitalcommons.uri.edu/oa_diss

\section{Recommended Citation}

Davies, Michael Hayden, "Children's Fears: The Development of a New Measure and Preliminary Findings Regarding Age and Sex Differences" (1982). Open Access Dissertations. Paper 1028.

https://digitalcommons.uri.edu/oa_diss/1028

This Dissertation is brought to you for free and open access by DigitalCommons@URI. It has been accepted for inclusion in Open Access Dissertations by an authorized administrator of DigitalCommons@URI. For more information, please contact digitalcommons-group@uri.edu. 
CHILDREN'S FEARS: THE DEVELOPMENT OF A NEW MEASURE AND PRELIMINARY FINDINGS REGARDING AGE AND SEX DIFFERENCES

BY

MICHAEL HAYDEN DAVIES

A DISSERTATION SUBMITTED IN PARTIAL FULFILLMENT OF THE REQUIREMENTS FOR THE DEGREE OF

DOCTOR OF PHILOSOPHY

IN

PSYCHOLOGY

UNIVERSITY OF RHODE ISLAND

1982 


\section{ABSTRACT}

This study reviews prior descriptive and self-report surveys of children's fears and presents the initial development of a new measure, the Fear Expression and Research Survey (F.E.A.R.S.). The F.E.A.R.S. represents an encouraging improvement over past measures: four clearly identifiable components emerged following the two administrations; the factor structure and degree of factorial invariance were satisfactory; the percentage of total variance accounted for by the 24-item core was $59 \%$ on Round one and $58 \%$ on Round Two; and the internal consistency (Alpha) coefficients were within acceptable limits. Evidence is presented to suggest that children's fears change with age on at least two of the four component scales, and girls are found to report a significantly greater degree of fear. Cautions and suggestions for future research are outlined. 


\title{
DEDICATION
}

\author{
to \\ Elizabeth and my parents \\ and \\ to the kids
}

Let the kids dance,

'cause they only got one chance...

-.- Sonny Terry 


\section{ACKNOWLEDGEMENT}

For their help, support, teaching, criticism, and patience, my sincere thanks go to:

Dr. Lawrence Grebstein, who from the first day we met to discuss my timetable gave me a loose rein, and who since then has been advisor, teacher, supervisor, running companion, and friend;

Dr. Jerry Cohen, whose help and suggestions, particularly with respect to the validation procedures for selfreport measures such as this, have had an important impact on this study;

Dr. Peter Merenda, who in class provided the sound fourdation from which this study springs, and whose advice has been sought repeatedly and has been much appreciated;

Dr. Wayne Velicer, who spent a great deal of time patiently teaching and encouraging me with this study;

Dr. George Fitzelle, who was a quietly supportive member of my comittee from the outset;

Mark Tavitian, classmate, statistical comrade, breakfast buddy, and good friend, who made all the work that much more fun;

Elizabeth, who encouraged me to give this a try; who tolerated the two-year commuting relationship, who withstood the inevitable pressures, and who married me in spite of it a.l1;

and my parents, who for as long as $I$ can remember demonstrated unswirving faith in my abilities, who tempered 
this faith with high yet attainable standards, who permitted me to make mistakes, who cheered my achievements, and who bought me Jocko, the stuffed monkey who drove the imaginary monkeys from my curtains when I was a child. 
Fear: the Construct $\ldots \ldots \ldots \ldots \ldots \ldots \ldots \ldots \ldots$

Etiological Considerations $\ldots \ldots \ldots \ldots \ldots \ldots \ldots$

Developmental Models .................. 5

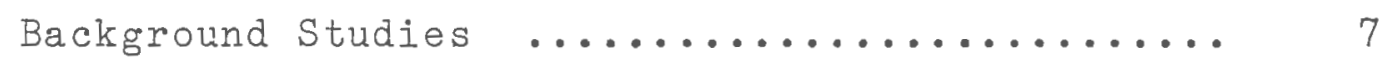

PRIOR INVENTORIES AND SURVEYS: DEVELOPMENTAL ....... 9 AND METHODOLOGICAI PROBLEMS

Early Broad Studies of Children's Fears ...... 9

Fear Survey Schedule $\ldots \ldots \ldots \ldots \ldots \ldots \ldots . \ldots . \ldots 12$

Fear Survey Schedule - II ................. 14

Fear Survey Schedule - III ............... 16

Fear Survey Schedule - for Children ........ 17

Louisville Fear Survey Survey for Children .... 19

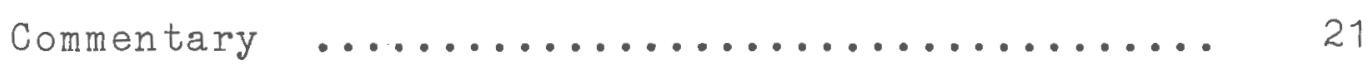

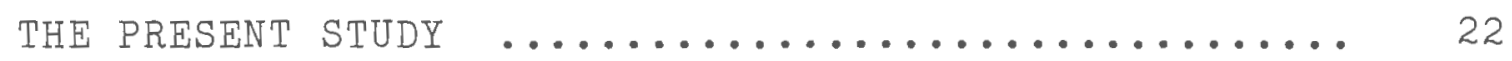

Developing a Measure of Children's Fears ...... 22

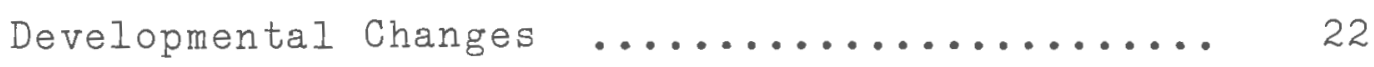

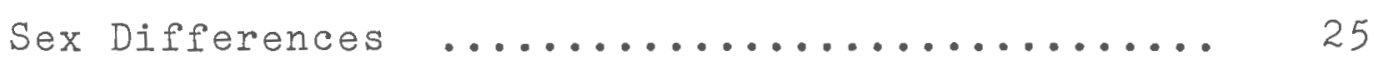

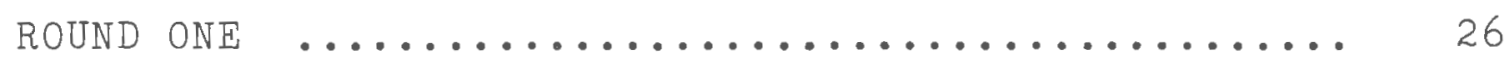

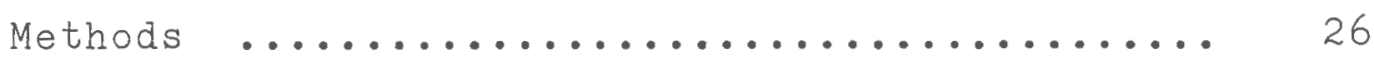

Item selection $\ldots \ldots \ldots \ldots \ldots \ldots \ldots \ldots$

Measurement of intensity $\ldots \ldots \ldots \ldots \ldots .27$

Subjects $\ldots \ldots \ldots \ldots \ldots \ldots \ldots \ldots \ldots \ldots \ldots \ldots \ldots \ldots \ldots$

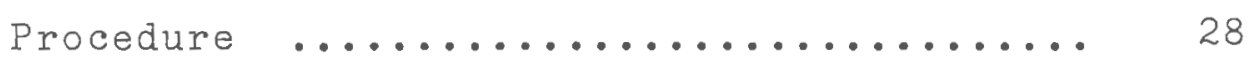

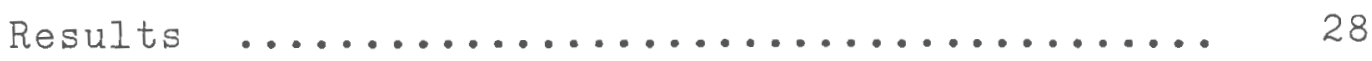


TABLE OF CONTENTS (continued)

PAGE

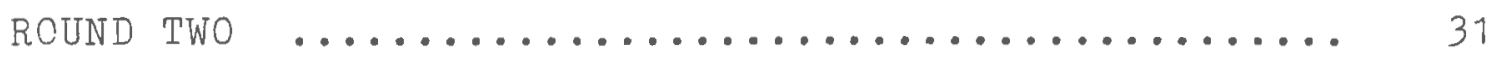

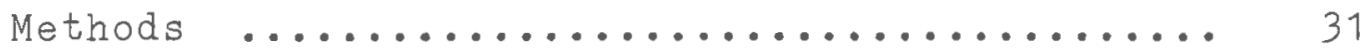

Item selection $\ldots \ldots \ldots \ldots \ldots \ldots \ldots \ldots . \ldots \ldots$

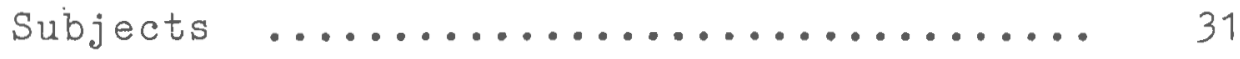

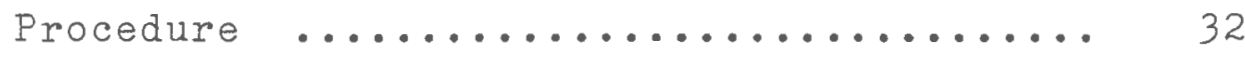

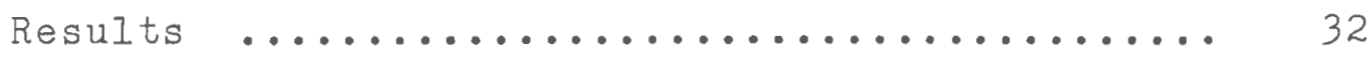

A comparison of Rounds one and Two $\ldots . . .32$

Age changes and sex differences $\ldots \ldots \ldots 38$

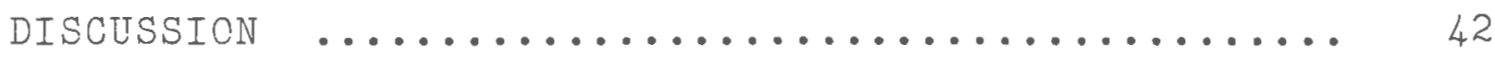

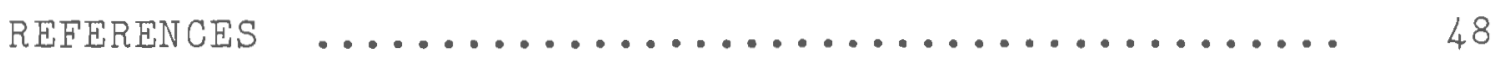

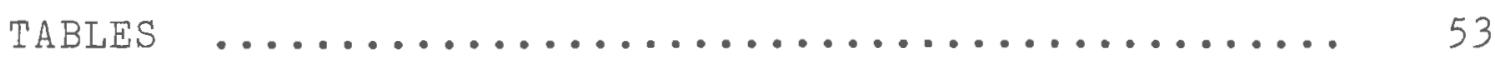

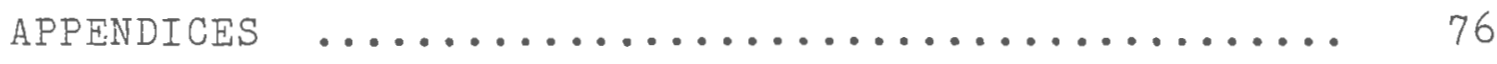


Table 1 : Round One Subject Distribution by

Grade and $\operatorname{sex} \ldots \ldots \ldots \ldots \ldots \ldots \ldots \ldots$

Table 2 : Round One 59-Item Varimax Rotated

Solution with 7 Components .......... 54

Table 3 : New Items Added to Round Two ......... 57

Table 4 : Round Two Subject Distribution by

Grade and Sex $\ldots \ldots \ldots \ldots \ldots \ldots \ldots \ldots$

Table 5 : Round Two 59-Item Varimax Rotated

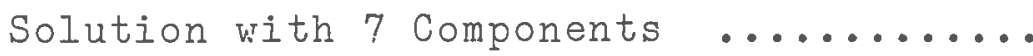

Table 6 : Round One 24-Item Varimax Rotated

Solution with 4 Components $\ldots \ldots \ldots \ldots$

Table 7 : Round Two 24-Item Varimax Rotated

Solution with 4 Components .......... 64

Table 8 : Scale Means and Standard Deviations .... 66

Table 9 : Item to Scale Correlations ........... 67

Table 10 : Interscale Correlations ............. 69

Table 11 : Round Two 34-Item Varimax Rotated

Solution with 4 Components $\ldots \ldots \ldots \ldots$

Table 12 : Internal Consistency (Alpha) for

Rounds one and Two $\ldots \ldots \ldots \ldots \ldots \ldots$

Table 13 : Round One Analyses of Variance and StudentNewman-Keuls Results for Age Changes .... 
LIST OF TABLE (continued)

PAGE

Table 14 : Round Two Analyses of Variance and StudentNewman-Keuls Results for Age Changes ..... 74

Table 15 : Analyses of Variance for Sex

Differences 
Apperdix A : Round One Fear Expression and

Research Survey (F.E.A.R.S.) (....... 76

Appendix B : 186-Item Varimax Rotated Solution

with 16 Components $\ldots \ldots \ldots \ldots \ldots \ldots .65$

Appendix C : Item Elimination in Round One ....... 96

Appendix D : Round Two Fear Expression and

Research Survey (F.E.A.R.S.) _...... 103

Appendix E : Item Elimination and Selection

for Rounds one and Two ............ 111

Appendix $F$ : Unrotated Factor Matrix -

Round one $\ldots \ldots \ldots \ldots \ldots \ldots \ldots \ldots \ldots \ldots$

Appendix G : Unrotated Factor Matrix -

Round Two $\ldots \ldots \ldots \ldots \ldots \ldots \ldots \ldots$ 


\section{INTRODUCTION}

This study has two major purposes: the first is to develop a psychometrically acceptable measure of children's fears; the second is to see whether or not children's selfrated fears change with age. Before these issues can be addressed, however, an understanding of fear as a construct, of the etiological theories regarding fear, of the available developmental models, and of the background work that has been done is necessary.

Fear: the Construct

Johnson and Melamed (1979) assert that among those involved with the assessment of children's fears

there seems to be some general consensus that fear connotes a differentiated response to a specific object or situation. Anxiety is a more diffuse, Iess focused response, perhaps best described as apprehension without apparent cause. (p. 107)

Croake and Knox (1973) and Geer (1965) make similar distinctions in their studies, whereas others (Rubin, Lawlis, Tasto, \& Namenek, 1969; Wolpe \& Lang, 1964) use the terms fear and anxiety interchangeably. While fear surveys tend to involve specific stimuli and anxiety surveys more general situations or concepts, this is not to say that an individual's fear and anxiety responses are therefore distinguishable on a physiological, emotional, or behavioral level. Without intending to imply that such a distinction is necessarily 
meaningful, the present study, with its focus on specific stimuli, will be termed a fear survey in order to be historically consistent.

Lang (1966), one of the pioneers in the development of fear surveys, "assumed that fear is a response, and further that it is a response expressed in three main behavioral systems: verbal (cognitive), overt-behavioral, and somatic" (p. 90). Lang found that different measures produced different fear intensity estimates and that the various aspects of the fear response seemed to be under the control of different variables. These findings prompted him to abandon the prevailing conceptualization of fear as a unitary feeling in favor of his three-part model. His conclusion was that: we should apply specific techniques to the different behavioral systems that we are trying to change - verbal, overt-motor, and somatic - and that therapy should be a self-conscious, multi-dimensional process. (p. 92)

Given the fact that the fear survey schedules employed thusfar, purportedly to measure the verbal component, have not been very reliable or valid instruments themselves, one cannot evaluate conclusively the validity of Lang's conceptual model. Again, without intending to argue for or against Lang's three-part model at this point, but in order to stay consistent with the literature (Johnson \& Melamed, 1979), the present study can be seen as at least encompasing the verbal 
dimension of which Lang speaks.

Etiological Considerations

The issue of the etiology of fear has been a topic of protracted and, at times, heated debate. Three of the principals in this debate have been McDougall, Watson, and Valentine.

McDougall postulated that every principal instinct had a primary emotion associated with it. For example, coupled with the instinct of flight was the emotion of fear. McDougall looked to comparative psychology to argue for a stable, unchanging character made up of the sum of man's innate tendencies and characteristics. He argued that these tendencies, at least in primitive form, could be found in higher animals as well as in man.

Watson, in his well-known work Behaviorism (1925) dismissed McDougall's assertions, saying "this elaborate group of McDougallian instincts does not exist (as instincts) ... They are valueless because no objective method was used in determining them" (p. 112). Throughout his published works, Watson argued forcefully against the inheritance of traits and the existence of instincts. He asserted that in considering the growth and development of a child one need not look within the individual. Instincts did not exist. Instead, parents and society were seen as building into the child those behaviors previously thought to be instinctual. Specifically:

Children's fears are home grown just like 
their loves and temper outbursts. The parents do the emotional planting and the cultivating. At three years of age the child's whole emotional plan has been laid down, his emotional pattern set. (Watson, 1928, p. 45)

In an earlier work, Watson postulated that fear, rage, and love were a part of "the original and fundamental nature of man" (Watson, 1980, p.278). Quickly, however, Watson moved to caution the reader in the use of these terms in any context other than reaction states. He suggested that fear is originally brought on by one of three causes or stimuli: loud sounds; the loss of support; and jolting when the child is either'just falling asleep or awakening.

Valentine (1930) challenged Watson's position based on observations of his own and other children. Perhaps his most provocative argument involved his notion of maturing instincts. According to Valentine, simply because an allegedly innate fear could not be demonstrated prior to six months of age did not mean that its emergence was due to experience. He suggested that researchers must allow enough time for the maturing instinct to emerge.

Valentine found no evidence of innate fears in children up to six months old, save in the areas of loud noises and loss of support. In children older than six months, he suggested that conflict was emerging between fear and curiosity with regard to animals. 
While Watson had argued that fear of the sea was of the same type as loss of support, Valentine found that his own children expressed fear of the sea even before they entered it. To argue here for Watson's theory of suggestion would be difficult, Valentine argued, for the fear was expressed even before the child had been in the water. As his children had appeared unafraid up until the age of two, Valentine went on to postulate that fear of the sea was one of the innate fears which took time to mature.

The aim here has not been to suggest that the debate of innate vs. learned fears has been, or perhaps ever can be, resolved. However, the implications of this debate transcend the academic, literary exchanges in which we find them. As Lightner Witmer (1911) so forcefully asserted throughout his career: "To ascribe a condition to the environment is a challenge to do something for its amelioration; to ascribe it to heredity too often means that we fold our hands and do nothing" (p. 231-232).

Developmental Models

While the present study seeks only to ascertain whether or not there appear to be developmental changes in children's self-rated fears, a brief look at the existing developmental models will place the results in a more meaningful context. Sameroff and Chandler (1975) describe three such models of development.

In the main-effect model the influences of constitution and environment are thought to act upon a child's 
development independent of each other. While this model grew out of retrospective studies and initially appeared to make sense, Sameroff and Chandler assert that prospective studies have not supported the predictions.

The interactional model can be understood best perhaps as a two-dimensional array of environments and constitutions where each child would have a particular developmental outcome for every combination of the two factors. The problem, as Sameroff and Chandler see it, is that such a model presumes constitution and environment to be static over time and such is clearly not the case.

The transactional model suggests that one needs to allow for the changing nature of both the environment and the individual. "Within this view, forces preventing the child's normal integration with his environment act not just at one traumatic point but must operate throughout his development" (p. 235).

Sameroff and Chandler clearly prefer the transactional model of development, and yet one must be careful to realize that not one of the three alternatives has received convincing empirical support, as yet. Nevertheless, it is interesting to note that adoption of the transactional model would help to clarify some of the issues in the etiological debate. This model would allow for the possibility that some fears may be innate, but it would also argue that in order for them to be maintained the environment would have to play a pivotal and continuous role. 
Background Studies

Prior attempts to determine the number and the intensity of fears in children and adults have included selfreport surveys (Braun \& Reynolds, 1969; Croake, 1969; Geer, 1965; Lang \& Lazovik, 1963; Miller, Barrett, Hampe, \& Noble, 1972; Scherer \& Nakamura, 1968; Wolpe \& Lang, 1964), structured interviews (Angelino, Dollins, \& Mech, 1956; Bauer, 1976; Jersild \& Holmes, 1933; Lapouse \& Monk, 1959), parent report (Miller, Barrett, Hampe, \& Noble, 1972), and direct observations in natural and experimental settings (Fazio, 1969; Geer, 1965; Jersild \& Holmes, 1933).

As noted by Anastasi (1976), a number of the fear survey schedules have been used clinically in conjunction with behavior modification programs. In this regard, they have served two major purposes: (a) to help pinpoint the treatment target (e.g., fear of snakes, fear of schoolrelated activities); and (b) to provide a pre- and post-test to assess treatment outcome and success.

The purpose of a fear survey schedule is to determine both the number and relative strength of fear eliciting stimuli in experimental subjects both before and after experimental intervention and in clinical patients before and after therapy. (Rubin, Lawlis, Tasto, \& Namenek, 1969, p. 381)

The bulk of the other inventories have been attempts to establish normative data or to test hypotheses. In the 
latter category, the most frequently posed research questions have involved whether or not children's fears change developmentally (Bamber, 1974; Bauer, 1976; Bondy, Sheslow, \& Garcia, 1981; Croake, 1969; Croake \& Knox, 1973; Jersild \& Holmes, 1933; Miller, Barrett, Hampe, \& Noble, 1972; Russell, 1967; Scherer \& Nakamura, 1968; Spiegler \& Liebert, 1970); whether males and females differ in number and/or intensity of fear (Bamber, 1974; Bernstein \& Allen, 1969; Bondy, Sheslow, \& Garcia, 1981; Croake, 1969; Croake \& Knox, 1973; Geer, 1965; Grossberg \& Wilson, 1965; Hannah, Storm, \& Caird, 1965; Lapouse \& Monk, 1959; Manosevitz \& Lanyon, 1965; Russell, 1967; Scherer \& Nakamura, 1968; Wilson, 1967); whether parents' fears correlate with their children's in number, type, and/or intensity (Hagman, 1932; Lapouse \& Monk, 1959); and the impact of socioeconomic status, intelligence, and culture (Angelino, Dollins, \& Mech, 1965; Bamber, 1974; Croake, 1969; Croake \& Knox, 1973; Lapouse \& Monk, 1959; Spiegler \& Liebert, 1970).

Bamber (1974) cites three methods of studying children's fears and briefly critiques each. He prefers questionnaires to direct observation because of the practical and ethical constraints inherent in the latter, and he sees problems with asking subjects to list their fears because of the risk of unreliable or incomplete recall. With questionnaires, standardization is possible, although he urges validation with actual situations.

Lanyon and Manosevitz (1966) concur with Bamber: 
"self-report paper and pencil measures of fear can be valid, if gross, indicators of fear behavior in an actual situation" (p. 259). They also argue that when one is constructing such a self-report measure, individual behavioral validation should be made whenever possible.

In "Behavioral treatment of children's fears: a review", Graziano, DeGiovanni, and Garcia (1979) are appropriately critical of the existing measures: "although fear-survey rating scales provide more information than the earlier approaches and have the advantage of standardization, their reliability and validity are still equivocal" (p. 812). However, their conclusion that "further research in this direction is of doubtful value" ( $p$. 813) seems overstated. A serious attempt must be made to improve both the construction of the instruments and our measurement procedures, for even modest improvements could lead to appreciable changes in reliability and validity. Prior Inventories and Surveys: Development and Methodological Problems

Early Broad Studies of Children's Fears

Jersild and Holmes' study of children's fears in 1933 is the most frequently cited antecedent to our more recent fear inventories. Their extensive study can be broken down into six components: (a) parents were asked to keep a twentyone day record of their preschool children at home; (b) they conducted interviews with parents regarding their children's fears; (c) fear episodes were observed and reported by 
teachers, parents, nurses and others; (d) they conducted private interviews with children aged five to twelve; (e) adults were asked to recall their own childhood fears; and (f) the children's responses were observed in an experimental situation.

They found that the greatest number of fears were in response to strange objects, persons, and situations, with strange persons the most frequent of all. Using frequency data and means, they suggested that the mean number of fears declined with age, especially with regard to fear of strange events, noises, high places, and falling. They asserted that fear of animals is more frequent in children three or older. Next they interviewed 398 children, aged five to twelve. In this sample they found that a large proportion of the named fears was more imaginary than real, and that, with the exception of fear of animals, there was no evidence of a decline with age in the frequency of fear of improbable dangers. They found that most of the fears mentioned were quite distant from actual dangers encountered in daily life.

While acknowledging the seminal nature of Jersild and Holmes' work with regard to developmental changes, the reader must be alert to more recent studies which depend upon these frequency data for empirical support. Jersild and Holmes' results clearly suggest that the developmental hypothesis deserves further attention. However, the lack of reliability and validity indices leaves it up to future research to pin down convincingly this area of study. 
Angelino, Dollins, and Mech (1956) had teachers ask their children to "list fears and worries you think persons of your own age group have" ( $p$. 274). In this manner, they hoped to get at areas which were not tapped by oral interviews, checksheets and questionnaires. They called it an "introspective-projective method" (p.274). The authors classified their results into ten categories: Safety; School; Natural Phenomena: Animals; Health; Economic and Political; Personal Appearance; Social Relations; Personal Conduct; and Supernatural. While these groupings may have had face validity, no evidence was given regarding their reliability or their construct or criterion validity. As such, along with Jersild and Holmes' (1933) work, this is seen best as a descriptive study - a study from which one may generate hypotheses but not reliable evidence.

Lapouse and Monk (1959) sought to gather normative data with the following objectives: (a) they wanted to ascertain the prevailing behavior of children of different ages, sex, race and socioeconomic background; (b) they, like the previous studies by Jersild and Holmes (1933) and Angelino et al. (1956), wanted to try to cluster behavior characteristics; and (c) they wanted to correlate these characteristics with measures of the general adjustment and functioning of the children.

While one might challenge the manner in which Lapouse and Monk chose to cluster their behaviors, one must laud their attempt to address the need for ascertaining reliability 
and validity. In particular, one must appreciate the accurately inconclusive nature of their discussion and conclusions. They stated that a large number of fears were widespread among children and that they were unable to suggest implications in terms of childhood psychopathology. We do not know if the fears and worries are indicative of maladjustment, personality deviation or emotional disturbance or if they are a concomitant of the wide range of developmental phenomena in essentially normal children. (p. 817)

Lapouse and Monk thus accurately state the open-ended nature of their findings and articulately set forth an important hypothesis for future consideration. Fear Survey Schedule

The Fear Survey Schedule (FSS) was developed by Lang and Lazovik (1963) to assess change in phobic behavior and generalized anxiety in experimental studies of desensitization.

The FSS is a list of 50 phobias each of which is rated by the subjects on a 7 point scale. An estimate was thus obtained not only of the subject's snake phobia, but of other related and unrelated fears. (p. 520)

The authors asserted that the items comprising the Fear Survey Schedule had been found in the past to have potential 
for eliciting neurotic anxiety.

Rubin, Lawlis, Tasto, and Namenek (1969), using a 5point scale (1 - no fear; 2 - a little fear; 3 - a fair amount; 4 - much; 5 - very much) and using a 122-item version, factor analyzed their results.

Several problems are evident from the outset. While they purport to use the Fear Survey Schedule, they provide no rationale for the leap from 50 to 122 items, except for a reference to a personal communication with Lang. One finds throughout the literature that items are added or dropped with little or no acknowledgement of the potential impact on the instrument's psychometric properties. Furthermore, while Rubin et al.'s use of a 5-point scale may have had a sound basis, the reader is not given the reasons for the switch from seven to five points. Also, no reliability or validity indices are given.

While the use of factor analytic procedures is certainly a step in the right direction, the reporting of the data by Rubin et al. is troublesome. They talk of accounting for ninety percent of the variance, and yet it is readily apparent that they mean common rather than total variance. Furthermore, because item loadings are given only on the factor selected for each item, one cannot ascertain the communalities from which one could compute the proportion of total variance accounted for. They make no mention of the method of factor extraction, internal consistency, factor structure, reliability or validity. 
Rubin et al. went on to compute a higher order factor analysis which, they claimed, suggested the presence of a general (g) factor. However, such a finding must await future confirmation with a measure of known, satisfactory psychometric properties. Fear Survey Schedule - II

Geer (1965) patterned the Fear Survey Schedule - II (FSS-II) after Akutagawa's 1956 unpublished 50 item scale which purported to include most commonly occurring fears. Geer developed his measure by giving his college student subjects ( 76 males, 48 females) an open-ended questionnaire on which they were to list their fears and rate the intensity on a three-point scale (mild, moderate, severe). Fifty-one of the one hundred eleven reported fears occurred more than once, and these became the items for the new scale. These fifty-one items were given to 161 male and 109 female subjects with a 7-point scale (1- none; 2 - very little; 3 a little; 4 - some; 5 - much; 6 - very much; 7 - terror). Using a summation, Geer calculated total scores for the males and females and stated that there was a sex difference ( $\underline{p}<.001)$, with females higher in score. Internal consistency was reported to be 0.94 . As indicated by Geer's study, he intended the Fear Survey Schedule - II to be primarily a research tool.

Rubin, Katkin, Weiss, and Efran (1968) sought to determine whether or not the FSS-II could be used as a gross measure of fear and to replicate Geer's (1965) earlier 
findings for males and females.

In his discussion of "Common methodological problems in factor analysis", Comrey (1978) cites failure to provide sufficient information for another researcher to replicate the study as one of the most common violations of scientific reporting. Such is the case with the study by Rubin et al.

The authors provided no information or rationale for the method of factor extraction employed which means that the reader cannot know whether all potentially meaningful factors were reported. While the communalities were included, the authors did not calculate the proportion of total variance accounted for by all of the factors and the proportion of variance accounted for by the individual factors. A brief calculation based on the reported communalities suggests that the proportions of total variance ranged from $58 \%$ to $73 \%$. These figures are of sufficient magnitude to justify the use of the schedule if other criteria are met.

Unfortunately, all is not as it appears. Upon further examination of the factor matrices, a discrepancy emerges between the reported and the actual communalities. Recomputing the communalities directly from the item loadings, one finds that the actual proportions of variance accounted for range from $28 \%$ to $37 \%$.

One is at a loss to explain the discrepancies. The only possible explanation would be that Rubin et al. calculated the communalities based upon eigenvalue-one extraction but then included only the reported, easily labeled factors. If 
this were the case, it would explain the error but not the procedure. In any event, a measure which accounts for only $37 \%$ of the total variance, at best, needs revision and improvement.

Since they were interested in essentially pure group factors, Thurstone's (1947) criteria for simple structure should be met as nearly as possible. One aim would be to have each variable measure only one factor to any substantial degree. Inspection of the rotated factor matrices reveals a number of complex variables. With so few pure-factor measures, it is often difficult to attain an appropriate rotational solution. In addition to these complex variables, there are a number of items whose contributions are near zero. As such, they should be eliminated from the survey.

With such poor simple structure, one cannot hope to achieve factorial invariance, and examination of Rubin et al's replicated results bears this out. Signs change, loadings change, and communalities change. All that remains relatively stable are the discouraging proportions of total variance accounted for.

Noted by their absence are any discussions by Rubin et al., or by others using the FSS-II subsequently, of internal consistency, reliability, or validity. These issues, as well as the lack of total variance accounted for, must be addressed before the FSS-II could be used with confidence. Fear Survey Schedule - III

The Fear Survey Schedule - III was designed by Wolpe 
and Lang (1964) for the rapid clinical assessment of a wide variety of common sources of fear. Wolpe and Lang divided the seventy-two fears into categories (Animal; Social or Interpersonal; Tissue Damage; IIIness and Death, and their Associations; Noises; Other Classical Phobias; and Miscellaneous) conceptually rather than based upon factor analytic results.

Manosevitz and Lanyon (1965) used the Fear Survey Schedule - III to study sex differences. Although the reliability and validity of Wolpe and Lang's schedule had not been established, they jeopardized what standardization there was by adding thirteen new items. In so doing, they, like others after them (Fazio, 1969; Spiegler \& Liebert, 1970), technically created a new measure.

Manosevitz and Lanyon computed total fear scores for males and females by suming the likert ratings for individual items. In this manner, they found that females had greater total fear scores than males $(\underline{p}<.01)$.

This practice of achieving total scores was utilized throughout the literature and yet, as Grossberg and Wilson (1965) caution, this method may not be as valid as it appears. For example, suppose there were two components: the first defined by twenty items; the second defined by ten items. Because of the disproportionate number of items on the first component, summing the ratings could be quite misleading. Fear Survey Schedule - for Children

The eighty items of the Fear Survey Schedule - for 
Children (FSS-FC) were selected on a conceptual basis similar to that used on the Wolpe-Lang scale (1964). After consulting graduate students and school personnel familiar with children's fears, the items were put in the following categories: School; Home; Social; Physical; Animal; Travel; Classical Phobia; and Miscellaneous. The items were then assigned randomly to odd-even positions within the scale so that the distribution of items from each category would be fairly even.

Each item was to be rated on a 5-point scale ( 1 - none; 2 - a little; 3 - some; 4 - much; 5 - very much). Using summed ratings, a method condemned by Grossberg and Wilson (1965), they arrived at a score for total number of fear items checked and for total degree of fear.

Scherer and Nakamura (1968) administered the Fear Survey Schedule - for Children to fifty-nine boys and forty girls, aged nine to twelve, and then factor analyzed the data in an attempt to develop subscales intended for use in clinical assessment and research in the area of children's fears. There was no mention of : (a) the method of extraction for the eight factors; (b) the factor structure; (c) the proportion of total variance accounted for; and (d) the reliability and validity indices. Perhaps of even greater importance, as the aim was to develop subscales, the internal consistency of each subscale should have been reported, rather than that of the whole scale $(\underline{r}=0.94)$. The authors' assertion that, while they tried to place each item on only one subscale, "If 
an item loading was relatively equal on two factors, the item was placed on both subscales" ( $p$. 179) serves to warn readers that there are complex variables on the survey.

Bondy, Sheslow, and Garcia (1981) attempted to establish test-retest reliability for the Fear Survey Schedule for Children using a Total Fear score and a High Fear score which was "determined by identifying the 10 items with the highest means within each grade and gender and then summing each subject's responses on these ten items" (p. 4). There are two major problems with this study: first, as Grossberg and Wilson (1965) suggested a number of years ago, total scores based upon summed ratings can be very misleading; and, second, Bondy et al. stretched even liberal standards for time elapsed in test-retest studies. By administering the test and the retest only one week apart, it is not surprising that they found the responses reliable $(\underline{p}<.001)$. Louisville Fear Survey for Children

The Louisville Fear Survey for Children is an 81-item inventory which purports to cover the full range of fear behavior in children from age four to age eighteen. The items were obtained from child and adult inventories available in 1967 and from the child clinical literature. The Fear Survey Schedule - for Children (Scherer \& Nakamura, 1968) was not known to the authors at that time.

The survey may be filled out by either children or adults and may be used for self-rating or rating by others. Each fear is rated on a 3-point scale which includes the 
categories of no fear, normal or reasonable fear, and unrealistic fear (excessive). Miller, Barrett, Hampe, and Noble (1972) reported split-half reliability for the fear survey in the general population to be 0.96 .

The authors administered the survey to the parents of 179 children ( 88 males, 91 females) and then subjected the $\underline{R}$ matrix to Principal Component Analysis. Miller et al. discussed three dimensions: fear of physical injury; natural events; and psychic stress. They reported the proportion of total variance accounted for to be only $36 \%$. While one can only speculate as to why the communalities were as low as they were, ranging from 0.04 to 0.61 , the fact remains that this survey does not measure the construct "children's fears" as well as one would hope.

Miller et al. also compared their parent-rating results to the child-ratings of Scherer and Nakamura (1968). Despite the lack of total variance accounted for, they claimed some evidence of factorial invariance.

Three factors (major fears, minor fears, and death) fall clearly within the domain of Factor I (physical injury), two Scherer and Nakamura factors (criticism and home/ school) represent Louisville Factor III (psychic stress), and Scherer and Nakamura Factor VIII is one component of the present Factor II (natural events). (p. 267) 
Commentary

In a review of this kind there is always a danger of appearing too harsh. However, while acknowledging the years that have passed since many of these surveys first appeared, as well as the statistical sophistication we presently enjoy, one must appraise each measure by current standards. Having done so, future research in the area of children's fears must avoid past mistakes and must make every effort to upgrade the psychometric properties of each chosen method. At present there are no known measures of children's fears which address satisfactorily the need for internal consistency, reliability, or validity. However, on a more optimistic note, the latter criticism is based more on the lack of complete and thorough psychometric development than upon negative findings. 
The Present Study

Developing a Measure of Children's Fears

Having acknowledged the contributions and the shortcomings of prior attempts, the primary task of this study is to construct a measure of children's fears which meets acceptable psychometric standards. Four aspects of scale development form the core of this effort:

(1) Item selection. The items included must represent as comprehensive a search for representative fear stimuli as possible.

(2) Reliability. The factor structure and the degree of factorial invariance across two administrations of the measure will be used to assess reliability.

(3) Validity. The proportion of total variance accounted for will be used as a necessary but not sufficient step in ascertaining construct validity.

(4) Internal consistency. Cronbach's Alpha will be used to determine the internal consistency of the component scales of the new fear measure.

While these four elements are critical to scale development, one must acknowledge from the outset that this study and the issues it addresses represent the initial stages in a process which, if done properly, will take years to complete. As such, this project represents an attempt to build a foundation from which a more comprehensive, more psychometrically sound scale will emerge in time. 


\section{Developmental Changes}

The results of prior research which addressed itself to the question of whether or not children's fears changed as a function of age were mixed. Some (Bamber, 1974; Bauer, 1976; Croake, 1969; Jersild \& Holmes, 1933; Miller, Barrett, Hampe, \& Noble, 1972; Scherer \& Nakamura, 1968) answered in the affirmative, and yet their results were so varied that one is hard-pressed to make general statements with certainty regarding these developmental changes.

Jersild and Holmes (1933) stated that:

According to the results of records kept by parents in their homes, the fear of strange or unfamiliar objects, persons, and situations reaches its peak at the age of two years. This result undoubtably is influenced largely by developmental factors. At the age of two the normal child is able to walk and is thus enabled to explore his environment and to meet many situations which were not accessible to him at an earlier time. (p.p. 117,118)

Croake (1969) found that, with the exception of some third graders, political fears (war, communists taking over) were most commonly held by his third and sixth grade subjects taken as a whole. For third graders, fear of natural phenomena (tornadoes, thunder and lightning) in the past was the most common fear; for sixth grade boys, supernatural phenomena (ghosts, the dark) were the most common past fears; and for sixth grade girls, natural phenomena and animals 
(bugs, wild animals) were the most common.

Miller, Barrett, Hampe, and Noble (1972), after comparing their results on the Louisville Fear Survey for Children with adult studies, concluded that fear of natural events tends to drop off with age, whereas fear of physical injury and psychic stress carry on throughout life.

Bauer (1976) suggested that children proceed from an undifferentiated global state to one where internal representations are increasingly differentiated from objective reality. For example, a child's global fear of ghosts, goblins, and monsters gives way over time to more specific fears which involve bodily injury.

Other studies which have addressed the developmental question have been negative in their findings (Bondy, Sheslow, \& Garcia, 1981), equivocal (Croake \& Knox, 1973), or mixed (Russell, 1967; Spiegler \& Liebert, 1970). Prior to reporting the results of their study Croake and Knox (1973) cited two common assumptions: (a) prior to age four, noise and noise related conditions are the most common fears; and (b) children from five to eight years old (particularly seven and eight) name animals, safety, and supernatural events as their most common fears. Their own results were equivocal, as the following statement indicates:

The supernatural fears espoused in child developmental texts, based on studies of several decades past, are far down the line in popularity today indicating that 


\section{these earlier studies now are valuable only in a historical context. ( $p \cdot 101)$}

Because prior results have not resolved the issue and because the improved psychometric properties of this measure of children's fears may lead to more meaningful results, the following hypothesis will be posed: children's fears, as measured by this fear survey schedule, change as a function of their age. Sex Differences

Prior research dealing with whether or not boys and girls differ in level of fear suggests that girls are more fearful than boys (Bamber, 1974; Bernstein \& Allen, 1969; Bondy, Sheslow, \& Garcia, 1981; Croake, 1969; Croake \& Knox, 1973; Geer, 1965; Grossberg \& Wilson, 1965; Hannah, Storm, \& Caird, 1965; Manosevitz \& Lanyon, 1965; Scherer \& Nakamura, 1968; Wilson, 1967). Russell (1967) found a significant three-way interaction between age, sex, and fear. Lapouse and Monk's (1959) results were inconclusive.

Despite the near unanimous findings indicating that girls are more fearful than boys, a number of these researchers were aware of social desirability as a potential confounding variable (Grossberg \& Wilson, 1965; Hannah, Storm, \& Caird, 1965; Manosevitz \& Lanyon, 1965; Wilson, 1967). Hannah et al. provide the most comprehensive assessment:

Sex differences in response ... may be a reflection of genuine temperamental differences 
between the sexes in susceptibility to fear, genetic in origin; they may be genuine differences in susceptibility to fear arising from differential environmental pressure to suppress or control fears; or they may indicate greater female willingness to admit fear, reflecting no genuine sex difference in emotional response. ( $p$. 1216)

The near unanimity of prior findings regarding sex differences is based upon measures which are not demonstrably reliable or valid. Because of this, and fully acknowledging the confounding variables which must be controlled for in time should the present results confirm earlier findings, the following hypothesis will be posed: there are differences in self-reported fears between boys and girls, as measured by this fear survey schedule. Girls are predicted to be more fearful.

\section{Round One}

\section{Methods}

Item selection. The first phase of this project involved an attempt to draw items from a broad spectrum: (1) from existing child and adult surveys and from the literature on children's fears (Castenada \& McCandless, 1956; Geer, 1965; Grossberg \& Wilson, 1965; Hallam \& Hafner, 1978; Lapouse \& Monk, 1959; Miller, Barrett, Hampe, \& Noble, 1972; Rubin, Katkin, \& Weiss, 1968; Rubin, Lawlis, Tasto, \& 
Namenek, 1969; Scherer \& Nakamura, 1968; Wolpe \& Lang, 1964); (2) from graduate students, clinical psychologists, and teachers working with children; and (3) from children themselves.

There were a number of repetitive and complex items. Repetitive items were dropped, while complex items (e.g., "bears and wolves", "dogs or cats", "worms or snails", and "germs or getting a serious illness") were broken down into separate items in order to avoid confusion in irterpretation later on.

This procedure resulted in selection of 200 items for Round One of the Fear Expression and Research Survey (F.E.A.R.S.). Using a random digits table (Snodgrass, 1977), these items were placed in random order for the administration of the measure.

Measure of intensity. A Likert-type scale from one to five (1- not at all; 2- a little bit; 3- some; 4-much; 5very much) was selected to provide adequate variance without asking the children to make unrealistically fine distinctions.

Subjects. The Round One measure was given to 258 children in second through sixth grade. Table 1 illustrates the distribution by grade and by sex. Two schools were involved: one a private elementary school in suburban Maryland and the other a private elementary school in suburban Massachusetts whose summer school student subjects came from public, private, and parochial schools. Parent permission was required for all children who participated in the study. For the most 
part, the children $(\bar{X}=9$ years, 7 months $)$ came from white, middle to upper-middle class familios.

Insert Table 1 about here

Procedure. The Round One Fear Expression and Research Survey (F.E.A.R.S.) of 200 items (see Appendix A) was administered class by class in a group setting. Because the time of administration varied from forty-five minutes to an hour and a half (the younger the child, the longer the time: in general), the order of the items was counterbalanced to address possible fatigue effects. The children gave their name, date of birth, grade, and sex.

Results

A number of Principal Component Aralyses (PCA) with varimax rotation were performed on this Round one measure. The Minimum Average Partial (MAP) method (Velicer, 1976) was used as a guide in determining the number of components to retain. The MAP method successively partials out components until the average squared partial correlation reaches a minimum. This minimum was used to estimate the proper number of components to retain rather than as a hard and fast rule. Inspection of the average squared partial correlations and the ability to interpret the components also were considered in the selection of the number of components.

Item loadings greater than or equal to .400 were considered as contributing to a component. Complex items (those 
with loadings greater than or equal to .400 on more than one component) and items loading less than .400 on all extracted components were dropped. The aim was to select the fifty to seventy-five items which best represented the extracted components.

An attempt was made to perform a Principal Component Analysis on the $200 \times 200$ matrix of item intercorrelations, but two negative eigenvalues emerged. In order for PCA to proceed, the $\underline{R}$ matrix must be Gramian (positive, semidefinite), and such apparently was not the case. This somewhat unusual situation may be caused by items on which most subjects respond uniformly at one end of the scale or the other. Review of the item means revealed six whose means were less than or equal to 1.11 , and these items were eliminated. A further attempt to perform a Principal Component Analysis on the 194 X 194 matrix of item intercorrelations resulted in one negative eigenvalue, so eight more items were dropped whose means fell below or were equal to 1.17 .

A successful Principal Component Analysis was performed on the $186 \mathrm{X} 186$ matrix of remaining item intercorrelations. The Minimum Average Partial method retained sixteen components (see Appendix B). By gradually eliminating complex and low items, fourteen Principal Component Analyses with varimax rotation were performed (see Appendix C for Item Elimination in Round One) until simple structure (Thurstone, 1947) was approached using 59 of the original 200 items. Table 2 illustrates the 59-item, seven component, varimax 
rotated solution to Round One. The items of this 59-item solution adhere rather well to Thurstone's concept of simple structure for orthogonal factors:

(a) most of the items have at least one near-zero component loading;

(b) with four common factors, most columns have at least four near-zero loadings;

(c) for every pair of columns, there are several variables with elements near zero in one column, but not in the other;

(d) for every pair of columns, a large percentage of the variables have loadings near zero in both columns;

(e) for every pair of columns, there are only a small number of variables with elements greater than near-zero in both columns.

Insert Table 2 about here

These seven components were labeled tentatively as follows: Death and Destruction; Social Acceptance; Surprises; Imagination; Social Conflict; Social Failures; and New Situations. In all, the 59-item solution accounted for roughly $53 \%$ of the total variance: $28.4 \% ; 8.1 \% ; 4.3 \% ; 3.4 \% ; 3.0 \%$; 2.9\%; and 2.8\%. Clearly, the Death and Destruction component dominates this solution. One would hope that as the measure is developed further the proportions of variances would become less disparate. 


\section{Round Two}

Methods

Item selection. The Fear Expression and Research Survey (F.E.A.R.S.) for Round Two was made up of: (1) the 59 Round One items which met the requirements of simple structure following Principal Component Analysis; and (2) 25 new items which were added in an attempt to build up the smaller Round One components. The primary focus hereafter will be upon the 59 items common to both rounds, and yet, in the spirit of an evolving measure, the impact of the new items will also be assessed. Table 3 lists the new items, and Appendix D contains the 84-item Round Two F.E.A.R.S. measure.

Insert Table 3 about here

Subjects. The Round Two Fear Expression and Research Survey was administered to 353 children in second through sixth grade. Table 4 indicates the distribution by grade and by sex. Two schools were involved, both public elementary schools in a suburban Massachusetts community. Again, the children ( $\bar{X}=9$ years, 6 months) came predominantly from white, middle to upper-middle class homes, and parent permission was obtained for all participants.

Insert Table 4 about here 
Procedure. The Round Two measure was administered class by class in a group setting. The survey took between twenty and forty-five minutes, depending largely upon the age and reading ability of the child. Once again, the order was counterbalanced. The directions remained the same. $\underline{\text { Results }}$

A comparison of Rounds one and Two. In order to compare directly the Round Two results with those of Round one, only the 59 items common to both were considered initially. The impact of the new items on the theoretical and psychometric properties of the measure was determined separately.

A Principal Component Analysis with varimax rotation was performed on the 59 X 59 matrix of item intercorrelations. While the Minimum Average Partial method retained only four components, seven were forced to illustrate the problem of factorial invariance, or lack thereof, between Rounds One and Two. As can be seen by comparing Tables 2 and 5, the requirements of simple structure are met, by and large, but many items are not factorially invariant from Round One to Round Two.

Insert Table 5 about here

This degree of variability was not acceptable, so an attempt was made to find the core of items which remained invariant across the two administrations. The first step was to eliminate the items of the last two Round One components 
from both measures. Their relatively low scale means $(\bar{X}=$ 1.71 and 1.51) and the fact that their items were so far from invariant from Round one to Round Two prompted this decision. In addition, while many of the items of the surprises component were invariant, the mean of this potential scale was so low $(\bar{X}=1.43)$ that its retention on a measure of fear did not seem justified. From then on the items were eliminated on the basis of complexity, low loadings, and switching components. On the Death and Destruction component, five of the lower loading items were dropped to bring the number of items on the scale to ten.

The final result of this process of item elimination and selection (see Appendix E) was a 24-item measure which remained factorially invariant over Rounds One and Two. Only one item, "Nightmares", was complex on Round Two, and, as we shall see, when the new items were added it was no longer complex. Thus, the decision was made to retain that item. The MAP method retained three components on Rounds one and Two. Given these as estimates, an examination of the average squared partial correlations revealed that one could retain justifiably either three or four components. As the four component solutions were readily interpretable, and the addition of the fourth component made a meaningful distinction between the social items, four components were retained. Tables 6 and 7 illustrate the 24-item, four component solutions to Rounds One and Two (PCA with varimax rotation). 
Appendices $F$ and $G$ provide the unrotated factor matrices for each round. The four components were labeled Death and Destruction, Social Acceptance, Social Conflict, and Imagination. Death and Destruction was defined by items such as "Being hit by a car or a truck", "My heart stopping", and "Earthquakes"; Social Acceptance was defined by items such as "Looking foolish", "Not being liked", and "Being fat"; Social Conflict was defined by items such as "Arguing with my parents" and "Getting punished"; and Imagination was defined by items such as "Going to bed in the dark", "Sleeping with the door shut", and "Nightmares".

Insert Table 6 about here

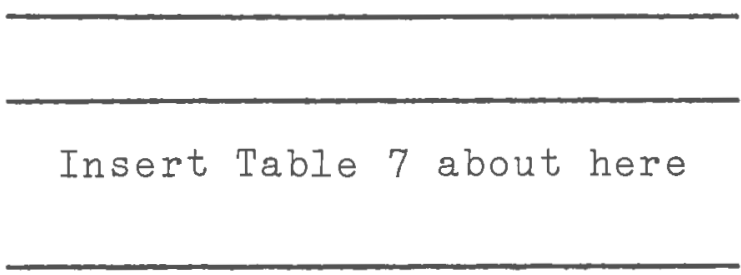

Once again, Thurstone's (1947) criteria for simple structure were met rather well, with the previously mentioned exception of "Nightmares" on Round Two. The proportion of total variance accounted for on Round one (59\%) and on Round Two (58\%) stayed virtually the same, as did the proportions accounted for by each of the four components: Death and Destruction (24\% and 25\%); Social Acceptance (12\% and $13 \%)$; Imagination (12\% and 10\%); and Social Conflict (11\% and $10 \%)$. While the Death and Destruction component still dominated, the gap between it and the others was no longer 
as great as it was following the 59-item solution.

Table 8 contains the scale means and standard deviations for the four components on both rounds. The items of the Death and Destruction component were the most feared; those of the Social Acceptarce component next; then those of the Social Conflict component; and, last, those of the Imagination component. This order was maintained for both rounds, and the magnitude of the paired scale means was similar, as well.

Insert Table 8 about here

The item to scale correlations for both rounds are provided in Table 9. Not surprisingly, given its magnitude, the items of the Death and Destruction component correlate more highly than those of the remaining three scales. The item to scale correlations of the other three scales, while consistently lower, are encouraging for a developing measure. Clearly, the aim over time is to find items which correlate as highly as possible with their given scale.

Insert Table 9 about here

Another important consideration in scale development is the degree to which the separate scales correlate with each other. Table 10 illustrates these interscale correlations. Ideally one would have as little overlap as possible. 
Remembering that the rationale for retaining four components rested in part on the desire to split the "social" items into Social Acceptance and Social Conflict, the relatively high correlations of .559 (Round One) and .556 (Round Two) between these two scales is not surprising. One must hope that by finding items which differentiate more clearly between these two scales the roughly $31 \%$ overlap will be reduced. The same applies to each of the other correlations: over time one seeks to reduce the degree of overlap as much as possible.

Insert Table 10 about here

The Round Two Fear Expression and Research Survey was made up of 84 items, twenty-five of which were added to the 59-item Round One solution. The aim, as mentioned earlier, was to build up the existing components with items thought to correlate with items already on the measure. As Death and Destruction already had ten items, the major focus was on the remaining, smaller components. Of the twenty-five new items, ten survived the item elimination process (see Appendix E): four were added to Social Acceptance; two were added to Social Conflict; and four were added to Imagination. Table 11 illustrates this 34-item (24-item core, plus 10 new items), four component, varimax rotated solution.

The proportion of total variance accounted for was $51 \%$. The drop from 59\% and $58 \%$ can be attributed to the fact that 
the communalities of the new items were lower, in general, than those of the items of the 24-item core. The breakdown of the $51 \%$ of the total variance was as follows: Death and Destruction, 18\%; Social Acceptance, 13\%; Imagination, 11\%; and Social Conflict, $9 \%$.

Insert Table 11 about here

After adding the items of each component and dividing by the number of items on that component, Cronbach's Alpha was computed for each of the four component scales. In this manner, each item was given equal weight, and, by dividing by the number of items on each scale, scales with differing numbers of items were more easily comparable.

The internal consistency coefficients (Alpha) for the 24-item Round One and Round Two measures ranged from a high of .92 for Death and Destruction to a low of .71 fcr Social Conflict on Round Two. In this latter case, all items of the scale contributed positively to the Alpha coefficient, and, while an Alpha of .71 is at the lower bounds of acceptability, one must remember that this scale was composed of only four items. Further development of the measure, as we shall see, will provide additional items which will enhance the internal consistency of this and the other scales.

The internal consistency (Alpha) of each of the four scales of the 34-item measure was computed in a manner similar to that used for the 24-item survey. As Table 12 
illustrates, the additicnal items enhanced the internal consistency of the three affected scales. Of particular note is the impact of the new items on the Imagination scale. Whereas "Nightmares" had depressed the Alpha coefficient of the four item Imagination scale on both rounds, the addition of four new items to this scale alleviated the problem. All four scales of the 34-item solution had internal consistency coefficients of .80 or better.

Insert Table 12 about here

Age changes and sex differences. Before addressing the questions of whether or not children's fears change as a function of their age and whether or not boys and girls differ in their self-reported levels of fear, one must emphasize that the results must be viewed as tentative. The F.E.A.R.S. measure is but a fledgling, and much remains to be done to establish convircingly its reliability and validity. However, by examining the issues of age changes and sex differences on Rounds one and Two, one may gain a sense of whether or not these questions should be pursued further.

Oneway analyses of variance were computed to determine whether or not there were significant differences between the children aged 7-12 on each of the four Round One scales. As there were only two 6-year-olds and two 13-year-olds on Round One and none of either on Round Two, only subjects ranging in age from 7 years, 0 months, to 12 years, 11 months, 
were included in these oneway analyses of variance.

As Table 13 indicates, the oneway ANovA results for Death and Destruction, Imagination, and Social Acceptance were significant at or beyond the $\underline{p}<.05$ level. In order to ascertain which age pairs differed significantly, the Student-Newman-Keuls procedure (using $\mathrm{e}<.05$ ) was employed.

On the Death and Destruction scale the 7-year-clds were significantly different from the 11-year-olds, and the 12year-olds were significantly different from the 7-, 8-: 9-, and 10-year-olds. Fear of the items comprising the Death and Destruction scale appeared to drop off with age.

On the Imagination scale the 9-year-olds differed significantly from the 12-year-olds with the 9-year-olds reporting the greatest fear. There was no discernible trend.

The oneway analysis of variance was significant for the Social Acceptance scale, and yet no pairs were significantly different according to the Student-Newman-Keuls procedure. The issue of unequal n's may have entered in here, as there were only twenty-seven 7-year-olds (low mean of 1.90), as opposed to fifty-two 11-year-olds (high mean of 2.38). In any event, with the exception of the 12-year-olds, fear of the items comprising the Social Acceptance scale appeared to increase with age.

One might speculate that the $\mathrm{dip}$ in 12-year-old reported fears on this scale was influenced by their status within the schools. The measure was administered in the late spring and early summer, so that the 12-year-olds (sixth graders) 
were about to finish or had finished at their present school. Adopting a "Ifraid of nothin" posture with an unknown researcher would not be surprising for children leaving familiar surroundings ard heading into junior high in a different school.

Insert Table 13 about here

In an attempt to replicate the Round One findings, four oneway analyses of variance were computed for the Round Two scales, again using the 7-12 age range. As expected, Table 14 indicates that the oneway ANOVA results for Death and Destruction, Imagination, and Social Acceptance were significant at or beyond the $\mathrm{p}<.05$ level.

While the F ratio for Death and Destruction was significant at the $\underline{p}<.001$ level, none of the differences between pair means was significant according to the Student-NewmanKeuls procedure. However, the Scheffe procedure, generally more conservative, showed a significant difference ( $p<.05$ ) between the 7-year-olds and the 11-year-olds. Once again, the unequal n' ${ }^{\prime}$ s played a part in this unusual result. While the mean for the 12-year-olds was lower than that of the 11year-olds, the fact that there were only fifteen 12-year-olds (out of 353 subjects) prevented the difference between the 7- and 12-year-olds from reaching statistical significance. In order to ascertain the full impact of this small number of 12-year-olds, a oneway analysis of variance was 
computed for children aged 7-11. The difference, as Table 14 illustrates, was clear. According to the Student-NewmanKeuls procedure results, the 7-year-olds were significantly different from the 10- and 11-year-olds, and the 9-year-olds were significantly different from the 11-year-olds. As was the case on Round One, fear of the items comprising the Death and Destruction scale appeared to drop off with age. The Student-Newman-Keuls results for the Imagination scale encountered difficulties similar to those discussed above, and, once again, the Scheffe procedure produced a significant difference $(\underline{p}<.05)$ - between the 7 - and 10-yearolds. When the 12-year-olds were dropped from the analysis, the Student-Newman-Keuls procedure reported significant differences between the 7-year-olds and the 9-, 10-, and 11-year-olds. There was no trend common to Rounds one and Two for the Imagination scale, however.

On the Social Acceptance scale, the 12-year-olds were significantly different from all of the other age groups. For the most part, fear of the items which made up this scale appeared to increase with age, with a significart increase at the 12-year-old level. Of note here, in contrast to the Round one results where the 12-year-olds dropped below the 11-year-olds in reported fear on this scale, were the results for the Round Two 12-year-olds. More than half of the Round Two sixth graders had been students of the researcher in the past and, therefore, may not have been as reluctant to report accurately on this Social Acceptance scale. 
Insert Table 14 about here

Oneway analyses of variance also were computed to determine whether or not boys and girls differed in their levels of fear on each of the four scales. Table 15 demonstrates that, as predicted, girls reported a significantly higher level of fear than did the boys on all four scales. The only exception occurred on the Round Two Death and Destruction scale, where the difference was not significant.

Insert Table 15 about here

\section{Discussion}

This study suggests that the Fear Expression and Research Survey holds promise as an emerging measure of children's fears. The Principal Component Analyses performed on the 24-item measure for Rounds one and Two resulted in four clearly identifiable components. The criteria of simple structure and of factorial invariance were met, suggesting a satisfactory degree of reliability at this initial stage. The proportion of total variance accounted for (59\% and 58\%), viewed as a necessary but not sufficient first step in ascertaining construct validity, represented an encouraging leap from the previous highs of $37 \%$ on the Fear Survey Schedule II (Rubin, Katkin, Weiss, \& Efran, 1968) and $36 \%$ on the Louisville Fear Survey for Children (Miller, Barrett, Hampe, 
\& Noble, 1972). The internal consistency of each of the four scales was within acceptable limits.

The reader should note that the improved internal consistency of the four scales of the 34-item measure (all $\geq .80$ ) was gained at the expense of total variance accounted for (51\%). In time, one must strive to raise both the amount of total variance accounted for and the internal consistency of each scale by careful selection of new items. In this regard, Hallam and Hafner's (1978) caution is worth bearing in mind:

When the situation depicted by the items can be feared for different reasons and the relative frequencies of fears differ in different samples, variability of factor structure is only to be expected. (p. 5)

One has only to recall that the 24-item core of the F.E.A.R.S. measure emerged. from an original pool of 200 items to appreciate the care and selectivity involved in ading acceptable new items to the measure.

The subsequent development of this survey must include attempts to increase the overall item to scale correlations and the communalities of the items selected and to decrease the interscale correlations as much as possible. Items which better differentiate between the two social scales are highly desirable. Also, by building up the size of the smaller component scales over time, the disparity between scales with regard to the percent of total variance each 
accounts for should be reduced further.

While it is appropriate that the major emphasis is placed upon the four established scales, future research should not ignore the possibility of developing additicnal component scales. On the 84-item F.E.A.R.S. measure, several of the new items dealing with fear of new or novel situations (e.g., "Making rew friends", "Moving to a new neighborhood", "Going to a new school") showed promise in this respect. More items should be generated to see whether or not this potential new component scale can meet the criteria already met by the four existing scales.

The results of this study indicate that there are reasons to believe children's fears do change with age. Fear of the items which make up the Death and Destruction scale appears to be high in second grade and to drop off gradually to a low in sixth grade. The trend was replicated in Round Two. Fear of the items which comprised the Social Acceptance scale appears to increase with age. Whether this is a steady rise or a sudden rise, as the Round Two results suggest, remains to be clarified. However, once again, the significant ANOVA results were replicated in Round Two. Although the oneway analyses were significant for the Imagination scale for both rounds, no common trend emerged.

The age changes revealed in this study are understandable to anyone in frequent contact with children of elementary school age. One has only to compare second graders diligently, if warily, crossing the street with a crossing guard and 
sixth graders cavalierly crossing wherever they wish to get a sense of the diminished fear of "being hit by a car or a truck". The parental plea, "Don't accept rides from strangers", sounds more frequently and more urgently in the ears of younger children ("Being kidnapped"). By sixth grade children have an increased sense of being able to take care of themselves. "Going to jail" is no longer something which might happen to them beyond their control or as a result of a minor indiscretion.

The increasing fear of the items of the Social Acceptance scale also make sense, and one could speculate that if the measure were given to 7 th and 8 th graders the fears on this scale would be as high or higher. Puberty, whether viewed physiclogically or emotionally, is a time when acceptarce of self and by peers becomes of paramount importance. The intriguing question which future research must resolve is whether there is a gradual increase, as the Round One results suggest, or a sudden burst, as the Round Two results indicate.

While the oneway ANOVA results for both rounds replicated earlier findings with regard to sex differences (with the exception of the nonsignificant finding on Death and Destruction, Round Two), one must remember Hannah, Storm, and Caird's (1965) earlier advice: at this point, we cannot tell whether the reported sex differences are the result of differential pressure in the environment to keep fears in check; whether the differences are genetic in nature; or 
whether they are a result of a greater willingress on the part of girls to acknowledge their fears. All we can be certain of at present is that girls do report a greater degree of fear on the four scales of the Fear Expression and Research Survey.

The results of the age change and sex difforence analyses provide evidence of concurrent criterion-related validity. The fact that the results were replicated across two administrations and that the results regarding sex differences replicated earlier findings lends further support to the stability of the measure.

Further research is still necessary before the Fear Expression and Research Survey may be used extensively. The reader is reminded that the subjects used thusfar were white, middle to upper-middle class children from predominantly suburban homes. Children from differing racial and socioeconomic backgrounds should be included in future administrations to ascertain the scope of the measure's utility. Wherever possible, the issue of social desirablity reeds to be addressed as well.

Additional studies involving convergent and divergent validation are necessary, as are ones which use the measure to compare fearful children (as determined by parent referral, professional diagrosis, or teacher rating) with rormal children. If the F.E.A.R.S. measure is able to make such a distinction, this would suggest an important clinical application. 
Despite the work which still remains to be done, it is clear that the items which comprise the Fear Expression and Research Survey form the core of a measure which, if developed properly, could make a significant contribution to our understanding of children's fears. 
References

Anastasi, A. Psychological Testing (4th Edition). New

York: MacMillan Publishing Company, Incorporated, 1976. Angelino, H. Dollins, J., \& Mech, E. V. Trends in the "fears and worries" of school children as related to socioeconomic status and age. The Journal of Genetic Psychology, 1956, 89, 263-276.

Bamber, J. H. The fears of adolescents. The Journal of Genetic Psychology, 1974, 125, 127-140.

Bauer, D. H. An exploratory study of developmental changes

in children's fears. Journal of Child Psychology and Psychiatry, $1976,17,69-74$.

Bernstein, D. A. \& Allen, G. J. Fear Survey Schedule (II): normative data and factor analyses based upon a large college sample. Behavior Research and Therapy, 1969, 7, $403-407$

Bondy, A. S., Sheslow, D., \& Garcia I. T. The reliability of the Fear Survey Schedule for Children across grade and gender - self-report of mother and children. UnpubIished manuscript, 1981.

Braun, P. R. \& Reynolds, D. J. A factor analysis of a 100-

item fear survey inventory. Behavior Research and Therapy, $1969,7,399-402$.

Castenada, A. \& McCandless, B. R. The children's form of the Manifest Anxiety Scale. Child Development, 1956, 27 (3), $317-326$. 
Comrey, A. I. Common methodological problems in factor analytic studies. Journal of Consulting and Clinical Psychology, $1978,46(4), 648-659$.

Croake, J. W. Fears of children. Human Development, 1969, $12,239-247$.

Croake, J. W. \& Know, F. H. The changing nature of children's fears. Child Study Journal, 1973, $\underline{3}$ (2), 91-105. Fazio, A. F. Verbal and overt-behavioral assessment of a specific fear. Journal of Consulting and Clinical Psychology, 1969, $33(6), 705-709$. Geer, J.H. The development of a scale to measure fear. Behavior Research and Therapy, 1965, 3, 45-53. Graziano, A. M., DeGiovanni, I. S., \& Garcia, K. A. Behavioral treatment of children's fears: a review. Psychological Bulletin, 1979, 86 (4), 804-830.

Grossberg, J. M. \& Wilson, H. K. A correlational comparison of the Wolpe-Lang Fear Survey Schedule and Taylor Manifest Anxiety Scale. Behavior Research and Therapy, 1965, 3, $125-128$.

Hagman, E. R. A study of fears of children of pre-school age. Journal of Experimental Education, 1932, 1 (2), $110-130$.

Hallam, R. S. \& Hafner, R. J. Fears of phobic patients: factor analyses of self-reported data. Behavior Research and Therapy, $1978,16,1-6$. Hannah, F., Storm, T., \& Caird, W. K. Sex differences and relationships among neuroticism, extraversion, and 
expressed fears. Perceptual and Motor Skills, 1965, 20, $1214-1216$.

Jersild, A. T. \& Holmes, F. B. A study of children's fears. Journal of Experimental Education, 1933, 2., 109-118. Johnson, S. B. \& Melamed, B. The assessment and treatment of children's fears. In B. Lahey and A. Kazdin (Eds.) Advances in Clinical Child Psychology. New York: Plenum Publishing Company, 1979.

Lang, P. J. Fear reduction and fear behavior: problems in treating a construct. In J. M. Shlien (Ed.) Research in Psychotherapy III. Washington: American Psychological Association, 1966.

Lang, P. J. \& Lazovik, A. D. Experimental desensitization of a phobia. Journal of Abnormal Psychology, '1963, 66 (6), $519-525$.

Lanyon, R. I. \& Manosevitz, M. Validity of self-reported fear. Behavior Research and Therapy, 1966, 4, 259-263. Lapouse, R. \& Monk, M. A. Fears and worries in a representative sample of children. American Journal of Orthopsychiatry, 1959, 29, 803-818.

Manosevitz, M. \& Lanyon, R. I. Fear Survey Schedule: a normative study. Psychological Reports, 1965, 17, 699703.

Miller, L. C., Barrett, C. L., Hampe, E., \& Noble, H. Factor structure of childhood fears. Journal of Consulting and Clinical Psychology, 1972, 39 (2), 264-268. Rubin, B. M., Katkin, E. S., \& Weiss, B. W. Factor analysis 
of a fear survey schedule. Behavior Research and Therapy, $1968, \underline{6}, 65-75$.

Rubin, S. E., Lawlis, G. F., Tasto, D. L., \& Namenek, T.

Factor analysis of the 122 item Fear Survey Schedule.

Behavior Research and Therapy, 1969, 7, 381-386.

Russell, G. W. Human fears: a factor analytic study of three

age levels. Genetic Psychology Monographs, 1967, 76,

$141-162$.

Sameroff, A. J. \& Chandler, M. J. Reproductive risk and the continuum of caretaking casualty. In F. D. Horowitz (Ed.) Review of Child Developmental Research IV. Chicago:

University of Chicago Press, 1975.

Scherer, M. W. \& Nakamura, C. Y. A Fear Survey Schedule for children (FSS-FC). Behavior Research and Therapy, 1968, 6, $173-182$.

Snodgrass, J. G. The Numbers Game: Statistics for Psychology.

Baltimore: The Williams and Wilkins Company, 1977. Spiegler, M. D. \& Liebert, R. M. Some correlates of selfreported fear. Psychological Reports, 1970, 26, 691-695. Thurstone, L. L. Multiple Factor Analysis. Chicago: University of Chicago Press, 1947.

Valentine, C. W. The innate bases of fear. Journal of Genetic Psychology, 1930, 37, 394-420.

Velicer, C. W. Determining the number of components from the matrix of partial correlations. Psychometrika, 1976, $41(3), 321-327$.

Watson, J. B. Behaviorism. New York: W. W. Norton \& Company, 
Inc., 1925.

Watson, J. B. Psychological Care of Infant and Child. New

York: W. W. Norton \& Company, Inc., 1928.

Watson, R. I. Basic Writings in the History of Psychology.

New York: Oxford University Press, 1980.

Wilson, G. D. Social desirability and sex differences in

expressed fear. Behavior Research and Therapy, 1967, 5, $136-137$.

Witmer, L. Criminals in the making. The Psychological

Clinic, 1911,4 , 221-238.

Wolpe, J. \& Lang, P. J. A fear survey schedule for use in

behavior therapy. Behavior Research and Therapy, 1964,

2, $27-30$. 
Table 1

Round One Subject Distribution by Grade and Sex

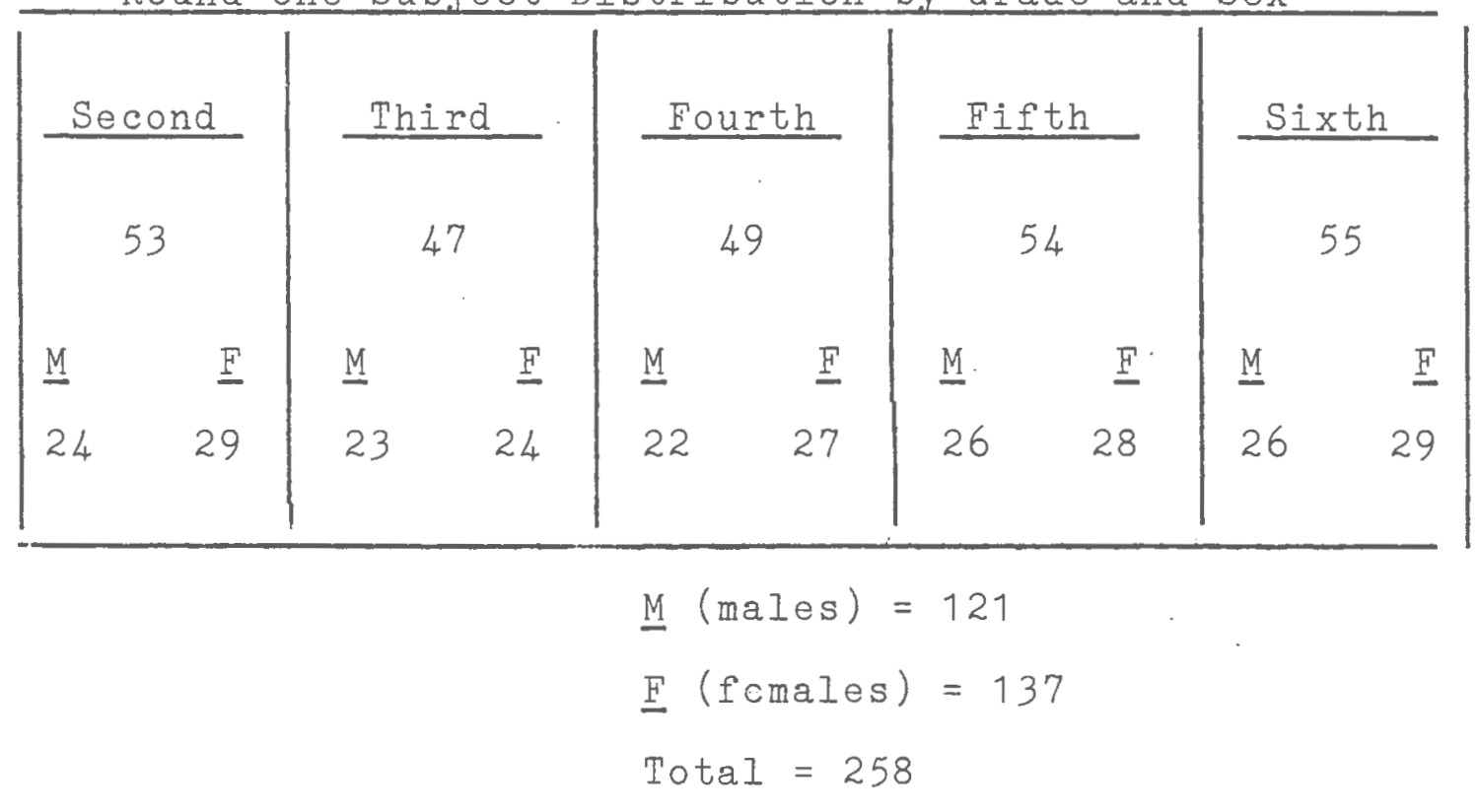


Table 2

Round One

59-Item Varimax Rotated Solution with 7 Components

lietting shot

Cancer

Being kidnapped

Going to jail

A robber breaking into our house

Explosions

Being in a car accident

Drowning

Being hit by a car or a truck

Quicksand

My heart stopping

War

Hurricanes

Earthquakes

Eating poisonous food

Hurting someone

Looking foolish

Not being liked

Being fat

People who seem crazy

Tough looking people

\begin{tabular}{|c|c|c|c|c|c|c|}
\hline 1 & 2 & 3 & 4 & 5 & 6 & 7 \\
\hline.$\overline{.751}$ & $\overline{.204}$ & $\overline{.050}$ & $\overline{.034}$ & $-\overline{.048}$ & $\overline{.062}$ &.$\overline{.003}$ \\
\hline .610 & .335 & .083 & .127 & .016 & .037 & .019 \\
\hline .716 & .155 & .102 & .087 & -.007 & .069 & .062 \\
\hline .689 & .307 & .031 & .101 & .042 & .120 & .142 \\
\hline .601 & .368 & .023 & .193 & .108 & -.029 & .101 \\
\hline .667 & .138 & .169 & .082 & .285 & -.081 & .114 \\
\hline .672 & .103 & .113 & .007 & .321 & .043 & -.042 \\
\hline .618 & .056 & -.047 & .083 & .159 & .183 & -.0 \\
\hline .766 & .057 & .011 & .100 & .199 & .186 & -.086 \\
\hline .692 & .107 & .057 & .129 & .082 & .150 & .248 \\
\hline .760 & .012 & .073 & .080 & .072 & .073 & .0 \\
\hline .680 & .059 & .204 & .015 & .088 & .015 & -.111 \\
\hline .658 & .019 & .082 & .064 & .253 & .031 & .258 \\
\hline .760 & .068 & .068 & .055 & .100 & .040 & .112 \\
\hline .70 & .217 & .058 & .105 & .001 & .050 & . \\
\hline
\end{tabular}

$\begin{array}{lllllll}.295 & .486 & .225 & .064 & .001 & .200 & .053\end{array}$

$\begin{array}{lllllll}.151 & .634 & .114 & .095 & .164 & .294 & .071\end{array}$

$\begin{array}{lllllll}.171 & .667 & .093 & .003 & .087 & .149 & .040\end{array}$

$\begin{array}{lllllll}.229 & .533 & .181 & .105 & .108 & .184 & -.004\end{array}$

$\begin{array}{lllllll}.209 & .594 & .143 & .158 & .034 & -.175 & .261\end{array}$

$\begin{array}{lllllll}.294 & .481 & .172 & .254 & .108 & -.199 & .334\end{array}$ 
Not being believed

Being teased

My parents arguing with each other

Being ignored

Bugs

Bridges

Heights

Carnival rides

Riding in a car

Riding in a bus

Seeing a fight

Worms

Crosing streets

Being in an elevator

Blood

Meeting boys

The dark

Going to bed in the dark

Thinking bad thoughts

Sleeping with the door shut

Nightmares $\frac{1}{.162} \quad \frac{2}{.610} \quad \frac{3}{.169}-\frac{4}{.039} \quad \frac{5}{.245} \quad \frac{6}{.151} \quad \frac{7}{.178}$

$\begin{array}{lllllll}.171 & .510 & .167 & .146 & .372 & .236 & .071\end{array}$

$\begin{array}{lllllll}.253 & .498 & .145 & -.098 & .318 & .205 & .001\end{array}$

$\begin{array}{lllllll}.127 & .407 & .146 & .286 & .244 & .302 & .279\end{array}$

$\begin{array}{llllllll}.107 & .177 & .501 & .175 & .062 & .017 & .075\end{array}$

$\begin{array}{lllllll}.011 & .156 & .628 & .201 & .039 & .036 & .061\end{array}$

$\begin{array}{llllllll}-.082 & .224 & .539 & .274 & .035 & -.059 & -.061\end{array}$

$\begin{array}{lllllll}.055 & .284 & .547 & .175 & -.142 & -.004 & .077\end{array}$

$\begin{array}{lllllll}.054 & .048 & .711 & .041 & .102 & .112 & .240\end{array}$

$\begin{array}{lllllll}.089 & .126 & .577 & -.041 & .043 & .240 & .207\end{array}$

$\begin{array}{lllllll}.237 & .117 & .535 & .218 & .241 & .103 & .088\end{array}$

$\begin{array}{lllllll}.130 & .103 & .512 & .145 & .095 & .243 & .145\end{array}$

$\begin{array}{lllllll}.169 & -.042 & .583 & -.009 & .302 & .279 & .239\end{array}$

$\begin{array}{lllllll}.178 & -.151 & .451 & .232 & .278 & .267 & .023\end{array}$

$\begin{array}{llllllll}.202 & -.003 & .347 & .453 & .160 & .211 & .075\end{array}$

$\begin{array}{lllllll}.168 & .066 & .242 & .445 & -.127 & .315 & .051\end{array}$

$\begin{array}{lllllll}.087 & .080 & .285 & .678 & .241 & .032 & .085\end{array}$

$\begin{array}{lllllll}.092 & .011 & .120 & .795 & .051 & .138 & .094\end{array}$

$\begin{array}{lllllll}.188 & .389 & .123 & .590 & .154 & .120 & .222\end{array}$

$\begin{array}{lllllll}.077 & .103 & .273 & .602 & .154 & .020 & .174\end{array}$

$\begin{array}{lllllll}.317 & .133 & .079 & .529 & .352 & .052 & .054\end{array}$ 
Arguing with my parents

Being hurt

Arguing

Getting punished

Being in a fight

Body odor

Getting a report card

Taking a test

Making mistakes

Farting

Sleeping at someone

else's house

Ugly people

Substitute teachers

Meeting girls

Meeting someone for

the first time

Talking to someone I don't know well

School

$\begin{array}{lllllll}\frac{1}{.291} & \frac{2}{.288} & \frac{3}{131} & \frac{4}{.129} & \frac{5}{.601} & \frac{6}{.004} & \frac{7}{.079} \\ .229 & .148 & .190 & .205 & .558 & .256 & .165 \\ .245 & .224 & .272 & .284 & .523 & -.028 & .149 \\ .259 & .303 & .083 & .134 & .597 & .155 & .202 \\ .365 & .146 & .182 & .289 & .553 & .050 & .168\end{array}$

$\begin{array}{lllllll}.172 & .385 & -.091 & .050 & -.102 & .491 & .001\end{array}$

$\begin{array}{lllllll}-.051 & .236 & .150 & .080 & .124 & .651 & .072\end{array}$

$\begin{array}{lllllll}.052 & .228 & .184 & .077 & .344 & .549 & .153\end{array}$

$\begin{array}{lllllll}.065 & .320 & .168 & .158 & .311 & .478 & .157\end{array}$

$\begin{array}{lllllll}.244 & .187 & .203 & .035 & .061 & .585 & .162\end{array}$

$\begin{array}{lllllll}.091 & -.048 & .189 & .367 & .003 & .428 & .237\end{array}$

$\begin{array}{lllllll}.208 & .014 & .110 & .230 & -.058 & .424 & .356\end{array}$

$\begin{array}{rrrrrrr}.125 & .161 & .286 & .083 & .049 & .088 & .577 \\ -.007 & .111 & .121 & .095 & .015 & .102 & .677 \\ .153 & .057 & .248 & .184 & .080 & .378 & .457\end{array}$

$\begin{array}{lllllll}.142 & .135 & .126 & .058 & .193 & .078 & .691\end{array}$

$\begin{array}{lllllll}.022 & .052 & .070 & .140 & .166 & .149 & .667\end{array}$ 
Table 3

New Items Added to Round Two

2. Asking strangers for directions

4. Going fast on a bike

6. Doing something dumb

8. Being yelled at

9. Big stores

17. Spider webs

22. Scraping my knee

24. Climbing ladders

26. Horror movies

32. Arguing with a teacher

33. Burping

38. Going to parties

40. Moving to a new neighborhood

41. Tooth aches

44. Sleeping in a strange place

46. Making new friends

47. Cutting my finger

50. Arguing with a friend

51. Being attacked from behind

52. Failing a test

54. Going to a new school

59. Graveyards

74. Haunted houses

81. Spooky stories

83. Stupid people 
Table 4

Round Two Subject Distribution by Grade and Sex

\begin{tabular}{|c|c|c|c|c|c|c|c|c|c|}
\hline \multicolumn{2}{|c|}{ Second } & \multicolumn{2}{|c|}{ Third } & \multicolumn{2}{|c|}{ Fourth } & \multicolumn{2}{|c|}{ Fifth } & \multicolumn{2}{|c|}{ Sixth } \\
\hline & & & & & & & & & \\
\hline M & $\underline{F}$ & $\underline{M}$ & $\underline{F}$ & $\underline{M}$ & $\underline{F}$ & $\underline{M}$ & $\underline{F}$ & $\underline{M}$ & $\underline{F}$ \\
\hline 25 & 20 & 33 & 37 & 37 & 35 & 37 & 44 & 39 & 46 \\
\hline
\end{tabular}

$M($ males $)=171$

$\underline{F}(f \in \operatorname{males})=182$

Total $=353$ 


\section{Table 5}

Round Two

59-Item Varimax Rotated Solution with 7 Components

Meeting boys

Hurting someone

Getting punished

Seeing a fight

Making mistakes

Arguing with my parents

Not being believed

Being hurt

Talking to someone I

don't know well

Tough looking people

Substitute teachers

People who seem crazy

My parents arguing with each other

Arguing

Being in a fight

Drowning

My heart stopping

Eating poisonous food

Explosions

Hurricanes

Being kidnapped

\begin{tabular}{|c|c|c|c|c|c|c|}
\hline 1 & 2 & 3 & 4 & 5 & 6 & 7 \\
\hline 106 &.$\overline{081}$ &.$\overline{123}$ &.$\overline{139}$ &.$\overline{291}$ &.$\overline{236}$ &.$- \overline{006}$ \\
\hline 31 & 15 & 38 & 028 & -.009 & 176 & -.08 \\
\hline & 53 & .028 & .113 & .044 & .112 & .01 \\
\hline & .123 & .171 & .057 & .247 & -.085 & .250 \\
\hline & .053 & .045 & 11 & .027 & .207 & .10 \\
\hline & .086 & .165 & .295 & -.023 & .113 & .04 \\
\hline 1 & .092 & -.048 & .177 & .102 & .401 & .073 \\
\hline 48 & .376 & .083 & .014 & . 181 & 0 & .16 \\
\hline 33 & .333 & .097 & .118 & .320 & .155 & -.002 \\
\hline 50 & .116 & .145 & .12 & .070 & 118 & .29 \\
\hline 497 & .081 & .088 & .041 & .262 & .069 & -.11 \\
\hline 404 & .148 & -.087 & .190 & .071 & .259 & .30 \\
\hline 509 & .144 & .093 & .043 & .055 & .200 & .18 \\
\hline 50 & .183 & .166 & .061 & .264 & .258 & .13 \\
\hline 15 & .204 & .128 & -.063 & .274 & .170 & .43 \\
\hline
\end{tabular}

$\begin{array}{lllllll}.240 & .640 & -.041 & .085 & .102 & .008 & .101\end{array}$

$\begin{array}{lllllll}.066 & .785 & .009 & .097 & -.032 & .030 & -.189\end{array}$

$\begin{array}{lllllll}.086 & .770 & .033 & .106 & -.028 & .085 & -.222\end{array}$

$\begin{array}{lllllll}.310 & .595 & .038 & .217 & .137 & -.065 & .053\end{array}$

$\begin{array}{lllllll}.018 & .697 & .096 & .124 & .076 & -.065 & .118\end{array}$

$\begin{array}{lllllll}.080 & .749 & .116 & .034 & .077 & .079 & .048\end{array}$ 
War

Being in a car accident

Earthquakes

Going to jail

Cancer

A robber breaking into our house

Quicksand

Being hit by a car or a truck

Getting shot

The dark

Nightmares

Thinking bad thoughts

Sleeping with the door shut

Going to bed in the dark

Being in an elevator

Taking a test

Riding in a bus

School

Getting a report card

Bridges

Crossing streets

Riding in a car $\frac{1}{.186} \quad \frac{2}{.568} \quad \frac{3}{.045}-\frac{4}{.048} \quad \frac{5}{230} \quad \frac{6}{.034} \quad \frac{7}{.215}$

$\begin{array}{lllllll}.158 & .681 & .116 & .041 & .129 & .188 & .147\end{array}$

$\begin{array}{lllllll}-.010 & .722 & -.006 & .029 & .0170 & .034 & .168\end{array}$

$\begin{array}{llllllll}.128 & .773 & -.001 & .037 & .093 & .048 & .045\end{array}$

$\begin{array}{lllllll}.066 & .709 & -.024 & .033 & -.045 & .0213 & .079\end{array}$

$\begin{array}{lllllll}.220 & .620 & .124 & .039 & .176 & .119 & .266\end{array}$

$\begin{array}{lllllll}.146 & .667 & .038 & .116 & .133 & .230 & .110\end{array}$

$\begin{array}{lllllll}.115 & .795 & .052 & .079 & .015 & .162 & .044\end{array}$

$\begin{array}{lllllll}.155 & .779 \quad .114 & -.004 & -.117 & .056 & .067\end{array}$

$\begin{array}{lllllll}.201 & .016 & .745 & .135 & .157 & -.020 & .116\end{array}$

$\begin{array}{lllllll}.342 & .235 & .401 & .084 & .181 & -.060 & .348\end{array}$

$\begin{array}{lllllll}.237 & .175 & .391 & .061 & .278 & .215 & .289\end{array}$

$\begin{array}{llllllll}.136 & .063 & .784 & -.026 & .118 & .161 & .131\end{array}$

$\begin{array}{llllllll}.049 & .107 & .782 & .116 & .071 & .080 & -.067\end{array}$

$\begin{array}{lllllll}.014 & .112 & .239 & .526 & .315 & -.026 & .158\end{array}$

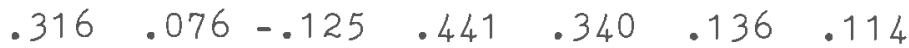

$\begin{array}{lllllll}.248 & .025 & -.012 & .496 & .018 & .067 & .289\end{array}$

$\begin{array}{llllllll}.336 & .059 & -.099 & .0331 & .057 & .054 & .076\end{array}$

$\begin{array}{lllllll}.275 & .081 & -.133 & .356 & .103 & .267 & .211\end{array}$

$\begin{array}{lllllll}-.036 & .113 & .183 & .527 & .193 & .046 & .291\end{array}$

$\begin{array}{lllllll}.022 & .263 & .309 & .420 & .389 & -.064 & .068\end{array}$

$\begin{array}{lllllll}.125 & .126 & .168 & .541 & -.046 & .084 & -.002\end{array}$

$\begin{array}{lllllll}.375 & .149 & .008 & .225 & .468 & .073 & .150\end{array}$
Meeting someone for the first time 
Worms

Blood

Bugs

Farting

Ugly people

Body odor

Looking foolish

Not being liked

Being fat

Being ignored

Being teased

Heights

Carnival rides

Sleeping at someone else's house

Meeting girls $\frac{1}{146} \quad \frac{2}{111} \quad \frac{3}{113} \quad \frac{4}{070} \quad \frac{5}{.665} \quad . \overline{218}-. \overline{002}$

$\begin{array}{lllllll}.298 & .224 & .037 & -.017 & .461 & -.041 & .236\end{array}$

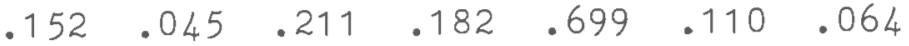

$\begin{array}{lllllll}.227 & .008 & .102 & .212 & .075 & .593 & -.143\end{array}$

$\begin{array}{lllllll}.258 & .116 & .260 & .231 & -.069 & .438 & .128\end{array}$

$\begin{array}{llllllll}.266 & .202 & .071 & .270 & -.0101 & .541 & .060\end{array}$

$\begin{array}{lllllll}.157 & .132 & .167 & -.021 & .083 & .568 & .431\end{array}$

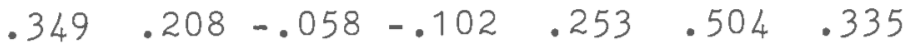

$\begin{array}{llllllll}.061 & .363 & .005 & -.095 & .167 & .583 & .159\end{array}$

$\begin{array}{lllllll}.340 & .222 & .087 & -.087 & .263 & .542 & .109\end{array}$

$\begin{array}{lllllll}.449 & .168 & -.001 & .049 & .211 & .465 & .192\end{array}$

$\begin{array}{lllllll}.092 & .053 & .123 & .246 & .195 & .035 & .442\end{array}$

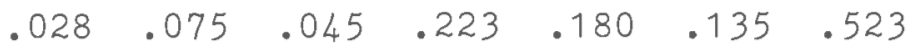

$\begin{array}{lllllll}.206 & .065 & .298 & .142 & -.109 & .130 & .387\end{array}$

$\begin{array}{lllllll}.176 \quad .129 & -.003 \quad .224 & -.129 \quad .100 \quad .493\end{array}$ 
Table 6

Round One

24-Item Varimax Rotated Solution with 4 Components

$\underline{\text { Item }}$

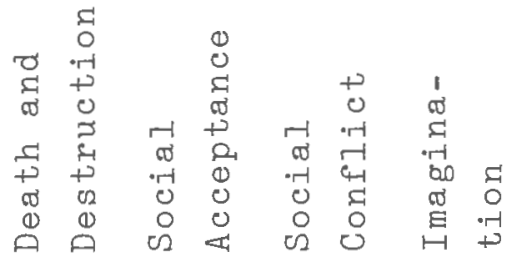

Getting shot

$\begin{array}{llll}.760 & .212 \quad .062 \quad .020\end{array}$

.627

Being kidnapped

$\begin{array}{llll}.752 & .181 & .023 & .105\end{array}$

.610

Going to jail

$\begin{array}{llll}.704 & .345 \quad .145 \quad .106\end{array}$

.647

Explosions

$\begin{array}{llll}.646 & .110 & .343 \quad .149\end{array}$

.569

Being in a car accident

$.647 \quad .109 \quad .383-.030$

.578

Being hit by a car or a truck

$.762 \quad .058 \quad .257 \quad .069$

.655

Quicksand

$\begin{array}{llll}.685 & .216 \quad .102 \quad .218\end{array}$

.574

My heart stopping

$\begin{array}{llll}.783 & .033 & .119 \quad .096\end{array}$

.638

Earthquakes

$\begin{array}{llll}.743 & .091 & .176 & .051\end{array}$

.594

Eating poisonous food

$\begin{array}{llll}.718 & .260 \quad .090 \quad .154\end{array}$

.615

Body odor

$.162 \quad .603-.073 \quad .024$

.396

Looking foolish

$\begin{array}{llll}.122 & .680 & .284 & .108\end{array}$

.570

Not being liked

$.141 \quad .696 \quad .154-.016$

.528

Being fat

$\begin{array}{llll}.204 & .636 & .171 \quad .120\end{array}$

.490

People who seem crazy

$\begin{array}{llll}.168 & .542 \quad .237 \quad .119\end{array}$

.392

Being ignored

$\begin{array}{llll}.107 & .526 & .293 & .358\end{array}$

.502 


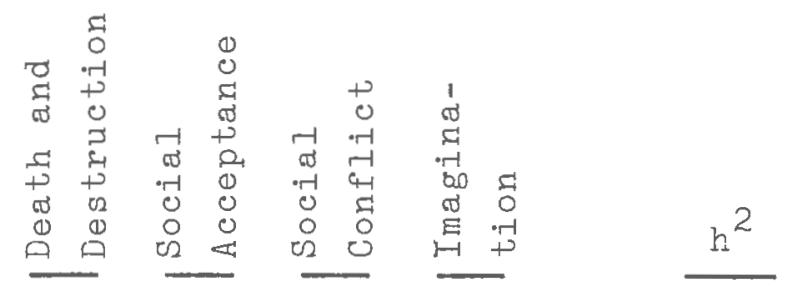

Arguing with my parents

$\begin{array}{llll}.226 & .211 \quad .769 \quad .052\end{array}$

.690

Being hurt

$\begin{array}{llll}.202 & .183 & .666 & .212\end{array}$

.563

Arguing

$\begin{array}{llll}.200 & .165 \quad .709 \quad .293\end{array}$

.656

Getting punished

$\begin{array}{llll}.215 & .279 \quad .654 \quad .196\end{array}$

.590

The dark

$\begin{array}{llll}.084 & .082 \quad .235 \quad .772\end{array}$

.665

Going to bed in the dark

$\begin{array}{llll}.095 & .090 \quad .043 \quad .827\end{array}$

.703

Sleeping with the door shut

$\begin{array}{llll}.075 & .139 & .123 & .791\end{array}$

.666

Nightmares

$\begin{array}{llll}.337 & .062 & .318 & .552\end{array}$

.523
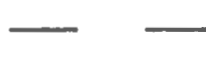
$\begin{array}{llll}5.66 & 2.85 & 2.84 & 2.69\end{array}$
$24 \% \quad 12 \% \quad 12 \% \quad 11 \%$

14.04

Eigenvalues

$59 \%$ 
Round Two

24-Item Varimax Rotated Solution with 4 Components

$\underline{\text { Item }}$

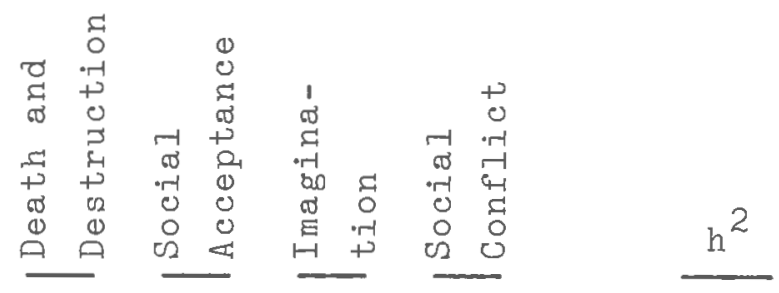

Getting shot

$.795 \quad .082 \quad .086 \quad .141$

.666

Being kidnapped

$\begin{array}{llll}.748 & .155 & .123 & .055\end{array}$

.602

Going to jail

$\begin{array}{llll}.767 \quad .228 & -.012 \quad .150\end{array}$

.663

Explosions

$\begin{array}{llll}.598 & .084 & .088 & .333\end{array}$

.483

Being in a car accident

$\begin{array}{llll}.680 & .295 \quad .152 \quad .113\end{array}$

.585

Being hit by a car or a

$\begin{array}{llll}.809 & .218 \quad .045 \quad .098\end{array}$

.714

Quicksand

$\begin{array}{llll}.652 & .296 \quad .084 \quad .165\end{array}$

.547

My heart stopping

$\begin{array}{llll}.814 & .004 & -.001 \quad .029\end{array}$

.663

Earthquakes

$\begin{array}{llll}.699 & .184 & .042 \quad .036\end{array}$

.526

Eating poisonous food

$\begin{array}{llll}.788 & .023 & .020 & .092\end{array}$

.630

Body odor

$\begin{array}{lllll}.183 & .537 & .094 & .136\end{array}$

.349

Looking foolish

$\begin{array}{llll}.062 & .760 & .237 & .064\end{array}$

.642

Not being liked

$\begin{array}{llll}.144 & .730 & .004 \quad .272\end{array}$

.628

Being fat

$.313 .685 \quad .012-.033$

.568

People who seem crazy

$.100 \quad .487-.046 \quad .398$

.408

Being ignored

$\begin{array}{llll}.177 & .643 & .102 & .266\end{array}$

.526 


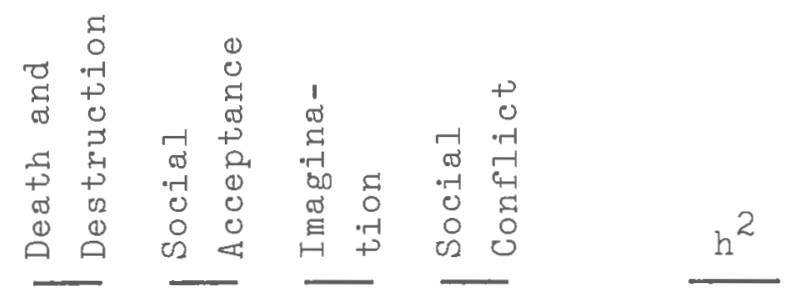

Arguing with my parents

$\begin{array}{lllll}.058 & .144 & .140 & .747 & .602 \\ .366 & .244 & .149 & .477 & .443 \\ .156: & .395 & .168 & .543 & .503 \\ .134 & .133 & .029 & .738 & .581\end{array}$

Being hurt

503

Getting punished

$\begin{array}{lllll}.007 & .064 & .824 & .193 & .720\end{array}$

The dark

$\begin{array}{lllll}.114 & .011 & .814 & .047 & .678\end{array}$

Going to bed in the dark

.114 .011 .814 .047

.724

Sleeping with the door shut

$.060 \quad .218 \quad .820 \quad .017$

.468

Nightmares

$\begin{array}{llll}.223 & .116 & .474 & .424\end{array}$

-

Eigenvalues

$\begin{array}{llll}5.89 & 3.18 & 2.45 & 2.39\end{array}$

13.91

$\%$ of total variance

$25 \% \quad 13 \% \quad 10 \% \quad 10 \%$

$58 \%$ 
Table 8

Scale Means and Standard Deviations

Death and Destruction

Scale

Item

Rnd 1 Rnd 2 Rnd 1 Rnd 2

Social Acceptance

$\begin{array}{ccccc}\bar{X} & 33.52 & 35.34 & 3.35 & 3.53 \\ \text { s.d. } & 10.91 & 10.77 & 0.35 & 0.34\end{array}$

Social Conflict

$\begin{array}{rrrrr}\bar{X} & 13.30 & 13.88 & 2.22 & 2.31 \\ \text { s.d. } & 4.85 & 5.09 & 0.36 & 0.34\end{array}$

$\overline{\mathrm{X}}$

8.42

8.76

2.10

2.19

s.d.

3.553 .10

0.24

0.31

$\overline{\mathrm{X}}$

7.05

7.18

1.76

1.79

Imagination

$\begin{array}{lllll}\text { s.d. } & 3.38 & 3.14 & 0.45 & 0.53\end{array}$


Table 9

Item to Scale Correlations

Round 1 Round 2

Scale: Death and Destruction

Getting shot

$.729 \quad .754$

Being kidnapped

$.697 \quad .701$

Going to jail

$.723 \quad .756$

Explosions

$.671 \quad .588$

Being in a car accident

$.647 \quad .685$

Being hit by a car or a truck

$.730 \quad .791$

Quicksand

$.680 \quad .668$

My heart stopping

$.721 \quad .711$

Earthquakes

$.700 \quad .657$

Eating poisonous food

$.720 \quad .709$

\section{Scale: Social Acceptance}

$\begin{array}{lrr}\text { Body odor } & .376 & .446 \\ \text { Looking foolish } & .584 & .607 \\ \text { Not being liked } & .536 & .644 \\ \text { Being fat } & .543 & .549 \\ \text { People who seem crazy } & .458 & .453 \\ \text { Being ignored } & .503 & .562\end{array}$


Round 1 Round 2

Scale: Social Conflict

Arguing with my parents

$\begin{array}{ll}.661 & .493 \\ .594 & .448 \\ .684 & .529 \\ .595 & .509\end{array}$

The dark

$.645 \quad .662$

Going to bed in the dark

$.628 \quad .576$

Sleeping with the door shut

$.629 \quad .625$

Nightmares

$.528 \quad .439$ 


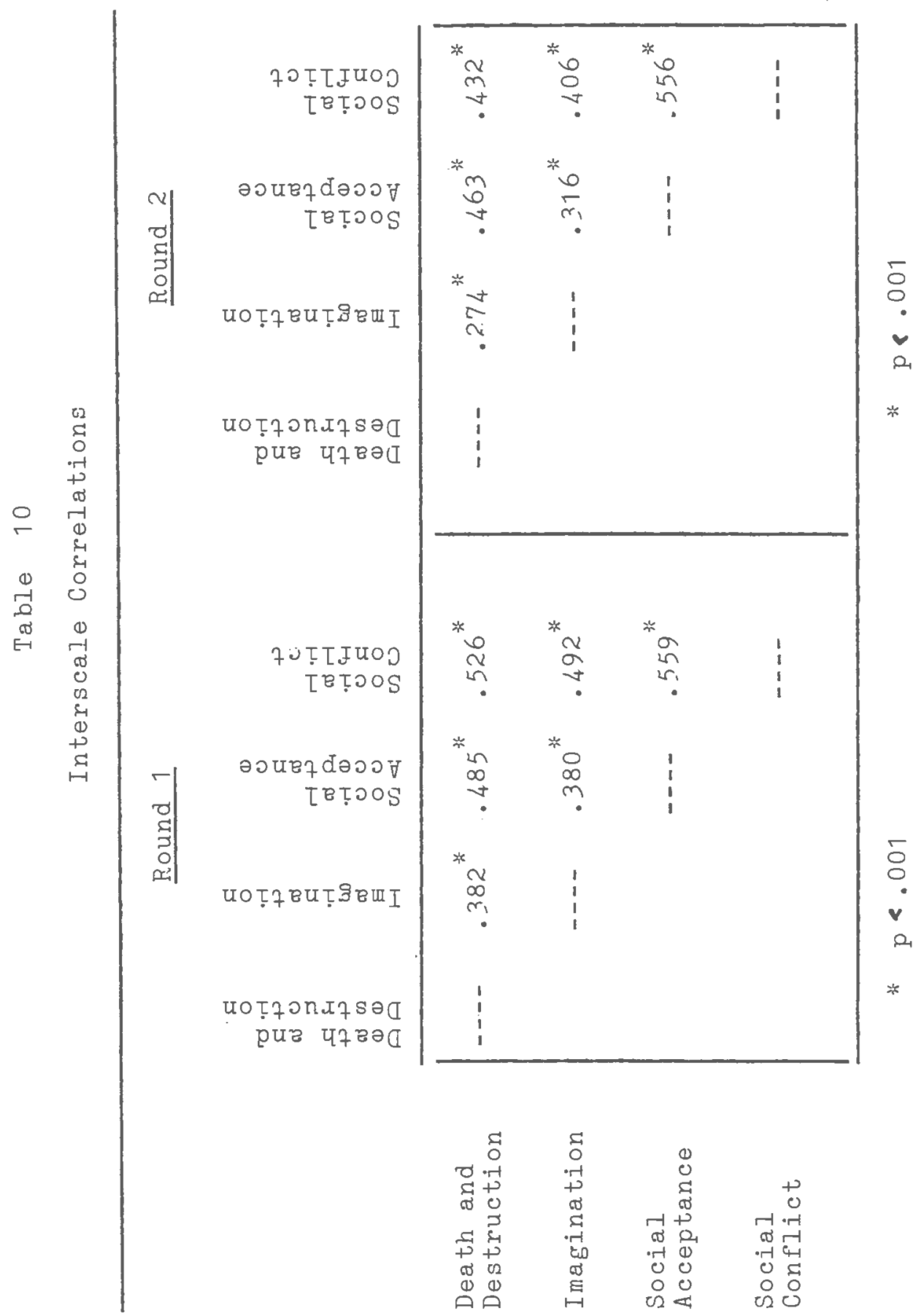


Table 11

Round Two

34-Item Varimax Rotated Solution with 4 Components

$\underline{\text { Item }}$

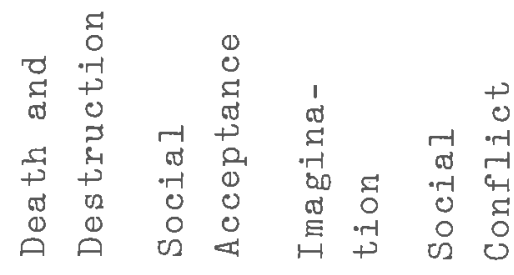

$n^{2}$

Getting shot

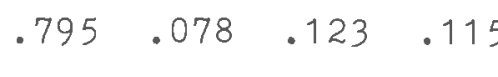

.666

Being kidnapped

$\begin{array}{llll}.740 \quad & .156 \quad .143 \quad & .042\end{array}$

.594

Going to jail

$\begin{array}{llll}.770 & .211 \quad .060 \quad .144\end{array}$

.662

Explosions

$\begin{array}{llll}.581 & .138 & .158 \quad .283\end{array}$

.462

Being in a car accident

$\begin{array}{llll}.675 & .292 & .197 & .089\end{array}$

.588

Being hit by a car or a truck

$\begin{array}{llll}.808 & .203 & .069 & .109\end{array}$

.711

Quicksand

$\begin{array}{llll}.653 & .272 \quad .180 \quad .111\end{array}$

.545

My heart stopping

$.812-.013-.000 \quad .068$

.664

Earthquakes

$.700 \quad .165 \quad .129-.010$

.534

Eating poisonous food

$\begin{array}{llll}.786 & -.011 & .013 \quad .169\end{array}$

.647

Body odor

$.182 \quad .556 \quad .106 \quad .090$

.362

Looking foolish

$.075 \quad .706 \quad .268 \quad .015$

.576

Not being liked

$\begin{array}{llll}.162 & .704 & .098 & .217\end{array}$

.579

Being fat

$\begin{array}{llll}.333 & .643 \quad .082 & -.089\end{array}$

.539

People who seem crazy

$\begin{array}{llll}.116 & .526 \quad .073 \quad .257\end{array}$

.362

Being ignored

$\begin{array}{llll}.194 & .586 \quad .126 \quad .274\end{array}$

.472

Doing something dumb (new)

$\begin{array}{llll}.073 & .464 & .140 & .377\end{array}$

.382

Burping (new)

$\begin{array}{llll}.052 & .546 \quad .166 \quad .186\end{array}$

.363 


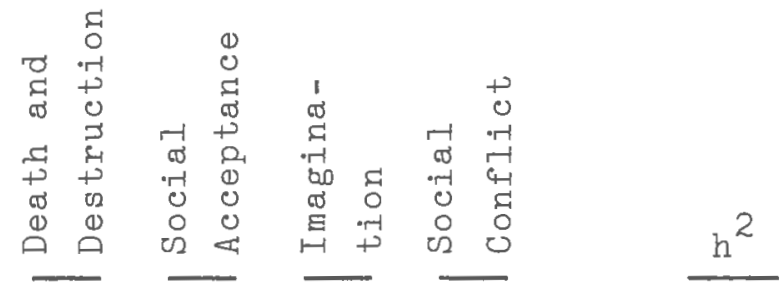

\begin{tabular}{|c|c|c|c|c|c|}
\hline Arguing with a friend (new) & .012 & .588 & .096 & .287 & .437 \\
\hline Failing a test (new) & .189 & .503 & -.021 & .253 & .353 \\
\hline Arguing with my parents & .059 & .177 & .186 & .680 & .532 \\
\hline Being hurt & .362 & .245 & .219 & .432 & .426 \\
\hline Arguing & .149 & .411 & .209 & .512 & .497 \\
\hline Getting punished & .134 & .148 & .109 & .718 & .567 \\
\hline Being yelled at (new) & .166 & .310 & .148 & .690 & .622 \\
\hline Arguing with a teacher (new) & .173 & .280 & .168 & .544 & .432 \\
\hline The dark & -.027 & .018 & .767 & .170 & .618 \\
\hline Going to bed in the dark & .076 & -.038 & .657 & .098 & .448 \\
\hline Sleeping with the door shut & .036 & .114 & .741 & .043 & .565 \\
\hline Nightmares & .204 & .139 & .648 & .220 & $\cdot 529$ \\
\hline Horror movies (new) & .043 & .263 & .629 & .113 & .479 \\
\hline Graveyards (new) & .207 & .269 & .460 & .118 & .341 \\
\hline Haunted houses (new) & .203 & .100 & .621 & .120 & .451 \\
\hline Spooky stories (new) & .160 & .246 & .619 & .053 & .472 \\
\hline Eigenvalues & 6.08 & $4 \cdot 47$ & 3.89 & 3.04 & 17.48 \\
\hline \% of total variance & $18 \%$ & $13 \%$ & $11 \%$ & $9 \%$ & 51 \\
\hline
\end{tabular}


Table 12

Internal Consistency (Alpha) for Rounds One and Two Scale Round One Round Two Round Two ${ }^{\mathrm{a}}$

Death and Destruction

.92

.92

.92

Social Acceptance

.76

.79

.84

Social Conflict

.81

.71

.80

Imagination

.79

.76

.83

ancluding ten new items 
Table 13

Round One

Analyses of Variance and Student-Newman-Keuls Results

for Age Changes

\begin{tabular}{|c|c|c|c|c|c|c|c|}
\hline \multirow[b]{2}{*}{ Scale } & \multicolumn{6}{|c|}{ Age } & \multirow[b]{2}{*}{ F ratio } \\
\hline & 1 & $\underline{8}$ & 9 & 10 & 11 & 12 & \\
\hline Death and & $\begin{array}{r}\mathrm{BC} \\
3.84\end{array}$ & $\begin{array}{r}D \\
3.64\end{array}$ & $\begin{array}{r}E \\
3.64\end{array}$ & $\begin{array}{r}F \\
3.42\end{array}$ & $\begin{array}{r}\mathrm{B} \\
3.10\end{array}$ & 2.78 & $\begin{array}{l}\mathrm{DEF} \\
(5,248)\end{array}$ \\
\hline Destruction & & & & & & & $5.13^{* * *}$ \\
\hline Imagination & 1.76 & 1.74 & $\begin{array}{r}B \\
2.05\end{array}$ & 1.93 & 1.66 & $\begin{array}{r}B \\
1.44\end{array}$ & $(5,248)$ \\
\hline & & & & & & & $2.52^{*}$ \\
\hline Social & 1.90 & 2.01 & 2.18 & 2.35 & 2.38 & 2.27 & $(5,248)$ \\
\hline Acceptance & & & & & & & $2.27^{*}$ \\
\hline Social & 2.34 & 2.05 & 2.28 & 2.27 & 1.97 & 1.87 & $(5,248)$ \\
\hline Conflict & & & & & & & 1.83 \\
\hline
\end{tabular}

$$
\begin{aligned}
& B-F=\text { significantly }(\underline{p}<.05) \text { different pairs } \\
& * \mathrm{p}<.05 \\
& \text { ** } \mathrm{p}<.01 \\
& \because \ddot{*}) \underline{p}<.001
\end{aligned}
$$


Table 14

Round Two

Analyses of Variance and Student-Newman-Keuls Results for Age Changes

\begin{tabular}{llllllll} 
& \multicolumn{9}{c}{ Age } \\
\cline { 2 - 6 } & $\underline{1}$ & 8 & 9 & 10 & 11 & 12 & Fratio
\end{tabular}

Death and

$\begin{array}{lllllll}4.10 & 3.58 & 3.78 & 3.38 & 3.27 & 3.16 & (5.347)\end{array}$

Destruction

$4.59^{* * * *}$

Imagination

$2.18 \quad 1.92 \quad 1.78 \quad 1.62 \quad 1.77 \quad 1.55 \quad(5,347)$

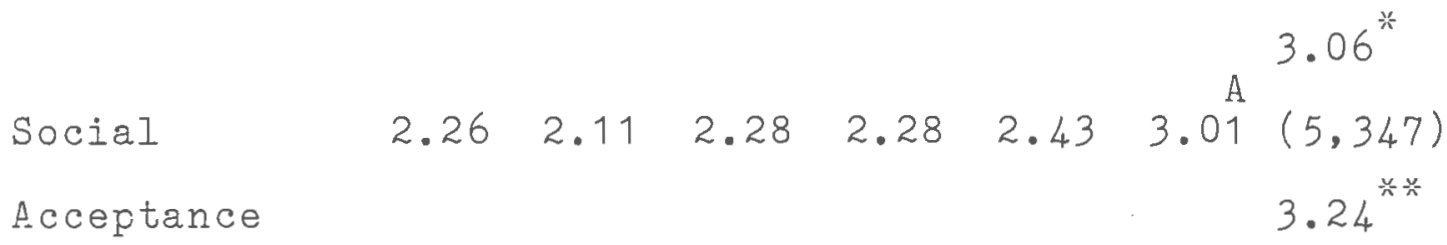

Social

$2.29 \quad 2.13 \quad 2.26 \quad 2.11 \quad 2.18 \quad 2.40 \quad(5.347)$

Conflict

$<1$

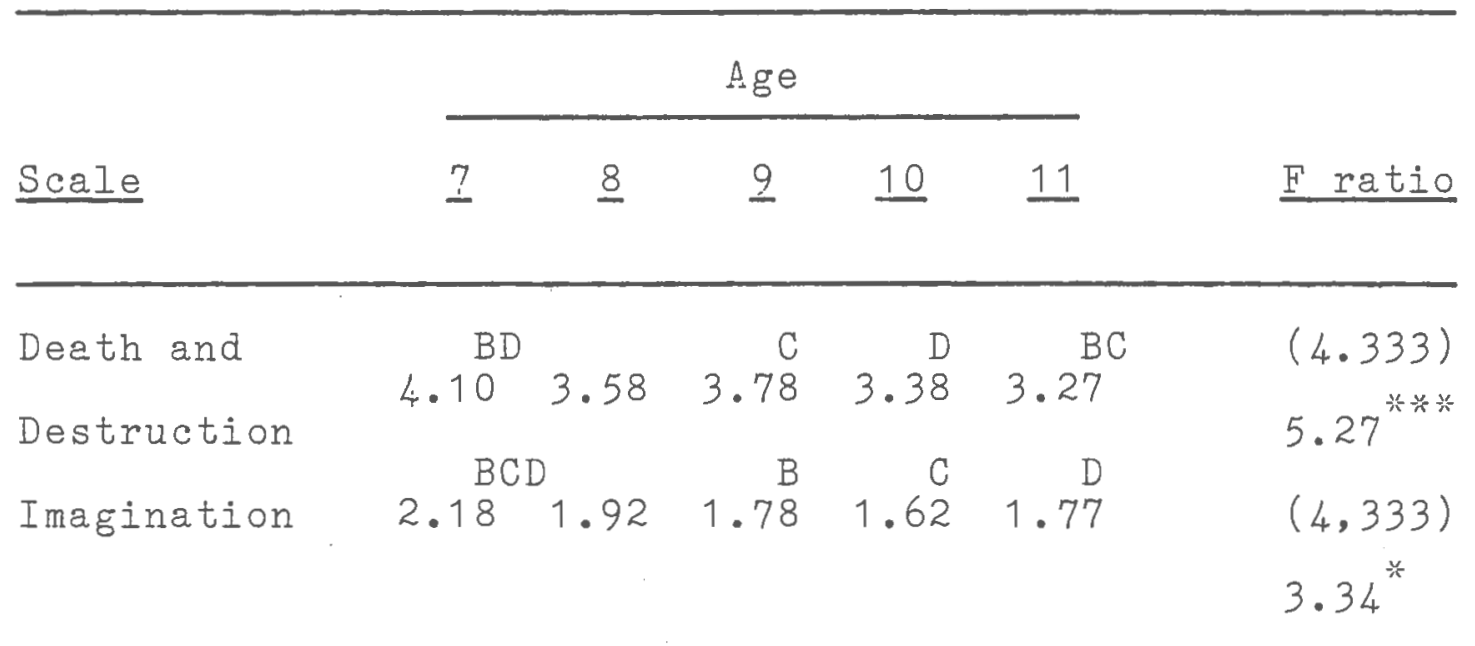

$A=\operatorname{sign} \cdot(\underline{p}<.05)$ different from

all pairs

$B-D=\operatorname{sign} .(\underline{p}<.05)$ different pairs

$$
\begin{gathered}
* p<.05 \\
* * p<.01 \\
* * x<.001
\end{gathered}
$$


Table 15

Analyses of Variance for Sex Differences

\begin{tabular}{|c|c|c|c|}
\hline Round & Scale & $\underline{d f}$ & F ratio \\
\hline \multirow[t]{2}{*}{ Ore } & & $(1,256)$ & $12.89^{* * * *}$ \\
\hline & Death and Destruction & & \\
\hline Two & & $(1,351)$ & 2.57 \\
\hline \multirow[t]{2}{*}{ One } & & $(1,256)$ & $12.92^{* * *}$ \\
\hline & Imagination & & \\
\hline Two & & $(1,351)$ & $13.20^{* * * * *}$ \\
\hline \multirow[t]{2}{*}{ One } & & $(1,256)$ & $9.85^{* * *}$ \\
\hline & Social Acceptance & & \\
\hline \multicolumn{2}{|l|}{ Two } & $(1,351)$ & $4.49^{*}$ \\
\hline \multirow[t]{2}{*}{ One } & & $(1,256)$ & $12.46^{* * * x}$ \\
\hline & Social Conflict & & \\
\hline \multicolumn{2}{|l|}{ Two } & $(1,351)$ & $5.39^{*}$ \\
\hline \multicolumn{4}{|c|}{$\therefore \quad * \underline{p}<.05$} \\
\hline \multicolumn{4}{|c|}{ 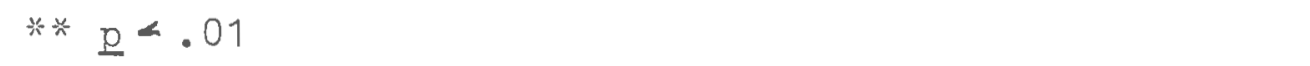 } \\
\hline$\ddot{*} \div$ 무 & .001 & & \\
\hline
\end{tabular}


Appendix A

ROUND ONE

FEAR EXPRESSION AND RESEARCH SURVEY

$$
\text { (F.E.A.R.S.) }
$$

The items you will find here are ones that children are sometimes afraid of. You are to circle the number that says how afraid you are of each item. Your choices are: 1 - not at all; 2- a little bit; 3 - some; 4 - much; 5 - very much. People are often afraid of different things and in different ways. Answer for yourself. There are no right or wrong answers. Your answers will not be shown to your teachers or to your parents. Please make sure you answer each item.

Before you begin, please fill in the spaces below.

Name

Date of Birth Grade

Check: Boy Girl

Name of your school 
not at a little

all

1. U.F.O.'s

2. Being hit by a ball

3. Snakes

4. Birds

5. Flying in a plane

6. Being stared at

7. Bugs

8. Choking

9. Tigers

10. Feeling angry

11. Swimming alone

12. Getting something in my eye

13. Getting shot

14. Hurting someone

15. Fire

16. New teachers

17. Body odor

18. Taking a bath or a shower

19. Going to the school nurse

20. Being locked up

21. Bridges

22. Getting poor grades

23. Crowds

24. Strange dogs

25. Looking foolish bit

some

much much

$$
4
$$

1

2

3

4

5

2

3

4

5

2

3

4

5

2

3

4

5

2

3

4

5

2

3

4

5

5

5

5

5

5

5

5

5

5

5

5

5

5

5

5

5

5

5 
not at a little

26. Wolves

27. Being adopted

28. Being seen naked

29. My parents leaving me

30. B1ood

31. Leaving home

32. Cancer

33. Meeting boys

34. BIizzards

35. Dirt

36. Losing control

37. Dead animals

38. Fainting

39. Being kidnapped

40. The dark

41. The ocean

42. Knives

43. Going to bed in the dark

44. Thinking bad thoughts

45. Razors

46. Germs

47. Dead bodies

48. BIushing

49. Doing something new

50. Spiders al1

\section{bit}

much

very

much

(1)

2

3

4

5

2

3

4

5

2

3

3

3

3

3

3

3

3

3

3

3

3

3

3

3

3

3

3

3

3

3

3

3
4

5

5

5

5

5

5

5

5

5

5

5

5

5

5

5

5

5

5

5

5

5

5

5 
51. Riots

52. Not being liked

53. Policemen

54. Playing rough games

55. Getting a report card

56. Substitute teachers

57. Getting sick

58. Being self-conscious

59. Handicapped people

60. Ants

61. Going to jail

62. Naked people

63. Sleeping with the door shut

64. Having to stay after school

65. Heights

66. Tornados

67. Being hungry

68. Being fat

69. Strangers

70. People who seem crazy

71. Tough looking people

72. Making another person angry

73. Sick people

74. Skunks

75. Roller coasters
2

3

4

5

2

3

3

3

3

2

2

2

2

2

2

2

2

3

3

4

5

5

5

5

5

5

5

5

5

23

2

3

2

2
3

3 
not at a little all

bit

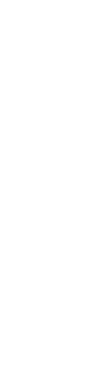

80. Deep water

81. Hell

82. Leaving friends

83. Bathrooms

84. Going to gym

85. Riding in a car

86. Giving a report in class

87. Riding in a bus

88. The devil

89. Going to the doctor

90. Hospital smells

91. Not being believed

92. Being left alone

93. Explosions

94. Escalators

95. Loud noises

96. Getting an electric shock

97. Strong winds

98. Shadows

99. Mailmen

100. Angry people
1
2

2

2

2

2

2

2

2

2

2

2

2

2

2

2

2

2

2

2

2

2

2

2

2

2 some

much

very

much

5

5

5

5

5

5

5

5

5

5

5

5

5

5

5

5

5

5

5

5

5

5

5

5

1 


\section{not at a little}

101. Being sent to the principal

2

3

102. A circus

2

3

103. Bees

2

3

104. Going shopping

2

3

105. Faces at the window

2

106. Falling

2

107. Being in a car accident

2

108. Being criticized

2

109. Rats

2

110. Thunder and lightning

2

111. Being a leader

2

112. Wetting my pants

2

113. Getting lost

2

114. Riding the train

2

115. Having an operation

2

116. Drowning

2

117. Mice

2

118. Bats (the kind that fly) 1

119. Death

1

120. Going to the hospital

1

121. Arguing with my parents 1

122. Being in a strange place 1

123. Big kids

1

124. Being hurt

1

125. Arguing

2

2

2

2

2

2

2

2 


\section{not at a little}

126. Someone in the family dying

127. Being teased

2

3

much

much

128. Closed places

129. Riding on the subway

2

3

4

130. Taking a test

2

3

4

5

131. Having to eat food I don't Iike

2

3

4

5

132. Being skinny

2

3

4

5

133. Getting burned

2

4

5

134. Looking different from others

2

135. Being hit by a car or a truck

2

3

5

136. Being called on in class 1

137. Getting punished

2

3

5

138. Hurting myself on purpose 1

2

3

5

139. Nightmares

2

3

5

140. Being punished by God

2

3

5

141. Large open spaces

2

3

142. Making mistakes

2

3

143. Being poor

2

3

144. Being hit by my parents

145. Tunnels

2

3

146. Ghosts

2

3

2

3

2

147. Being in a fight

2

148. Peeping toms

2

149. Meeting girls

2

150. Quicksand

2

3

3

4 
151. Guns

152. One person bullying another

153. Talking on the telephone 1

154. Camping out

155. Strange looking people

156. Farting

157. My parents arguing with each other

158. Firemen

159. Sudden noises

160. Russians

161. Being different

162. Meeting someone for the first time

163. Cemeteries

164. Sleeping at someone else's house

165. Closets

166. Cats

167. Going to the movies

168. Going to the dentist

169. Being accused of lying

170. My heart stopping

171. Basements

172. Seeing a fight

173. Strange shapes

174. Worms

175. Bad breath
2

2

2

2

2

2

2

2

2

2

2

2

2

2

2

2

2

2

2

2

2

2

2

2

2

1

3

4

5

5

5

5

5

5

5

5

5

5

5

5

5

5

5

5

5

5

5

5

5

5

5

5

5 
176. War

177. Being misunderstood

178. Attics

179. Wetting the bed

180. Being ugly

181. Going to parties

182. Hurricanes

183. Crossing streets

184. Talking to someone I don't know well

185. Ugly people

186. Being ignored

187. Being in an elevator

188. Faces in the curtains

189. Going crazy

190. Witches

191. Drains

192. Getting arrested

193. School

194. Throwing up

195. Getting cut

196. Earthquakes

197. Vacuum cleaners

198. Eating poisonous food

199. Bears

200. Ticks
2

2

2

2

2

2

2

2

2

2

2

2

2

2

2

2

2

2

2

2

2

2

2

2

2
3

4

5

5

5

5

5

5

5

5

5

5

5

5

5

5

5

5

5

5

5

5

5

5

5

5

5 


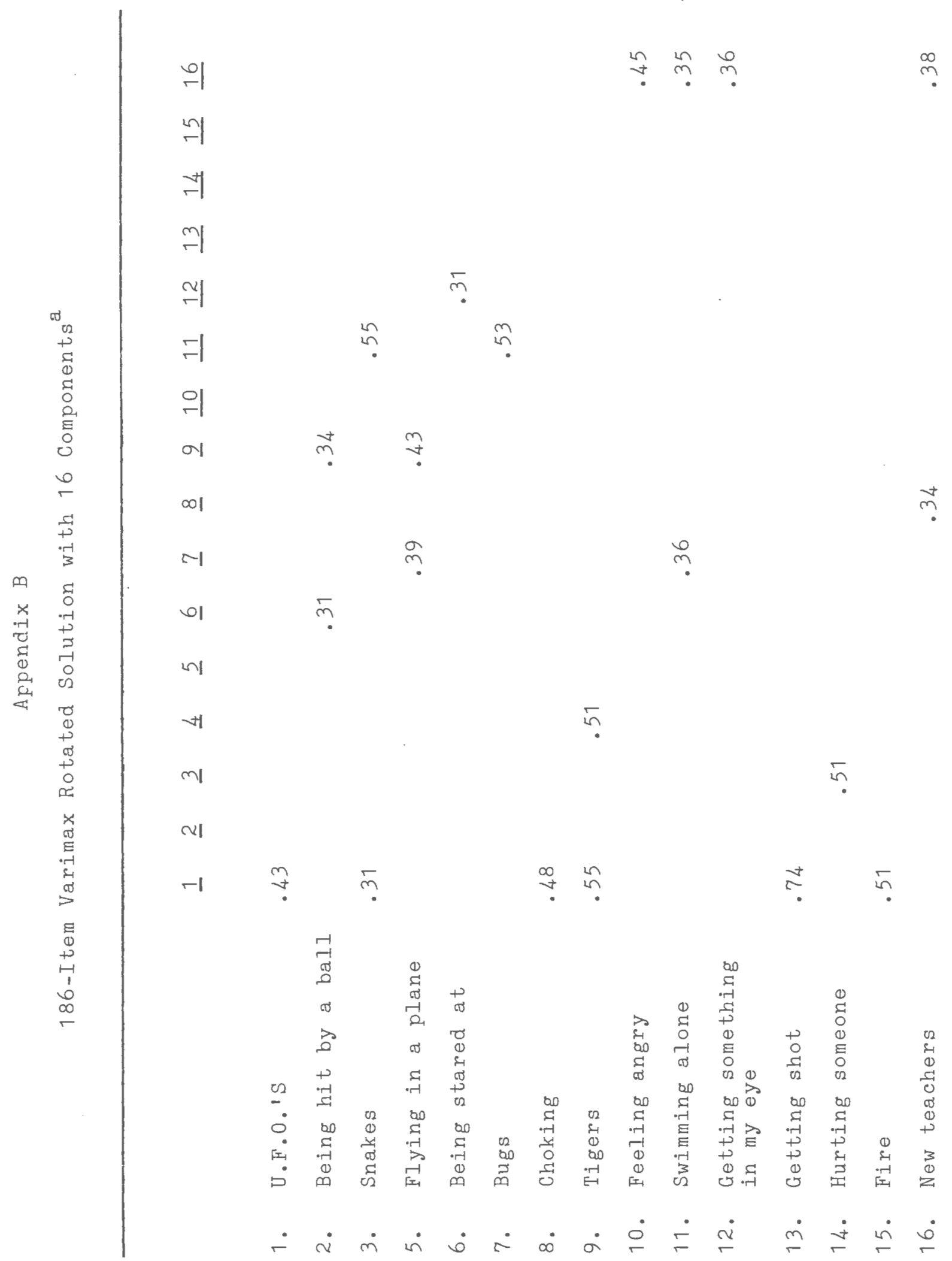




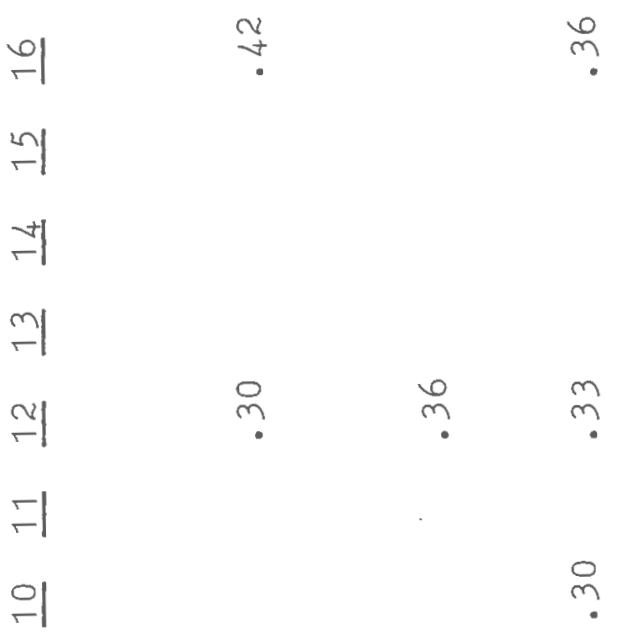

al

$\infty 1$

m

$-1$

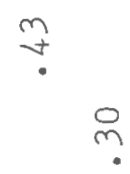

$m$

61

$\stackrel{\circ}{?}$

$\stackrel{0}{m}$

?

(n)

जा

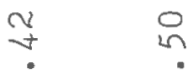

mi

$\stackrel{a}{m}$

$m$

NI

-1 in

in

in $m$

$\begin{array}{ccc} & & 02 \\ 0 & & 0 \\ 0 & & 0 \\ -1 & & 0 \\ 0 & 0 & 0 \\ 01 & 3 & 0\end{array}$

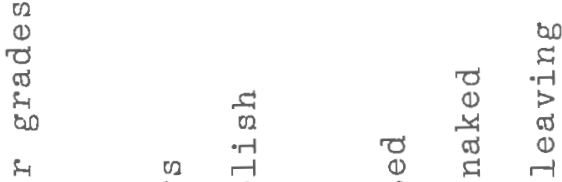

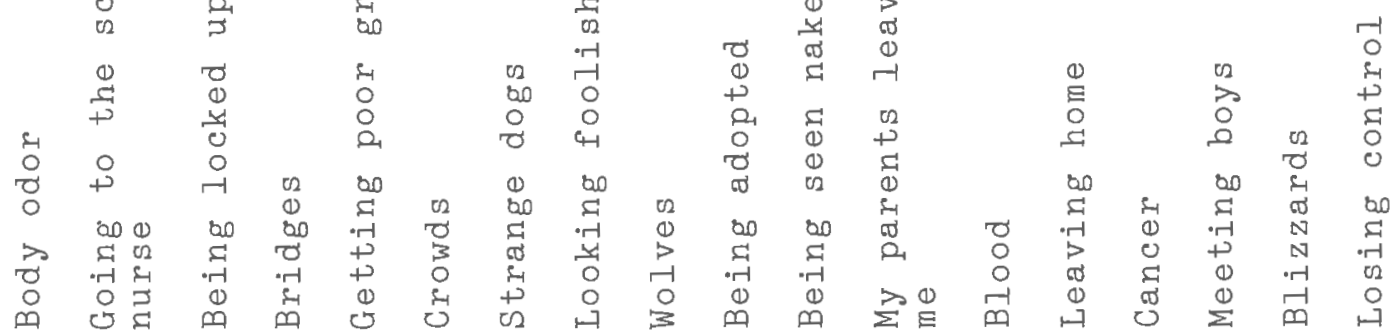

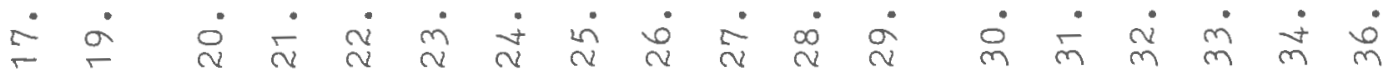


$\stackrel{0}{1}$

in

가

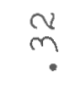

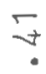

m

N1

5

$\stackrel{\sim}{m}$

?

이

al

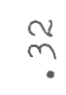

$\bar{m}$

$\infty 1$

$-1$

이

$\stackrel{\infty}{m}$

ำ

H

m

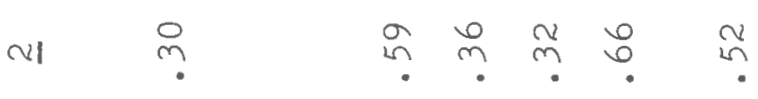

$\stackrel{a}{m}$

$m$

$-1 \quad$ in

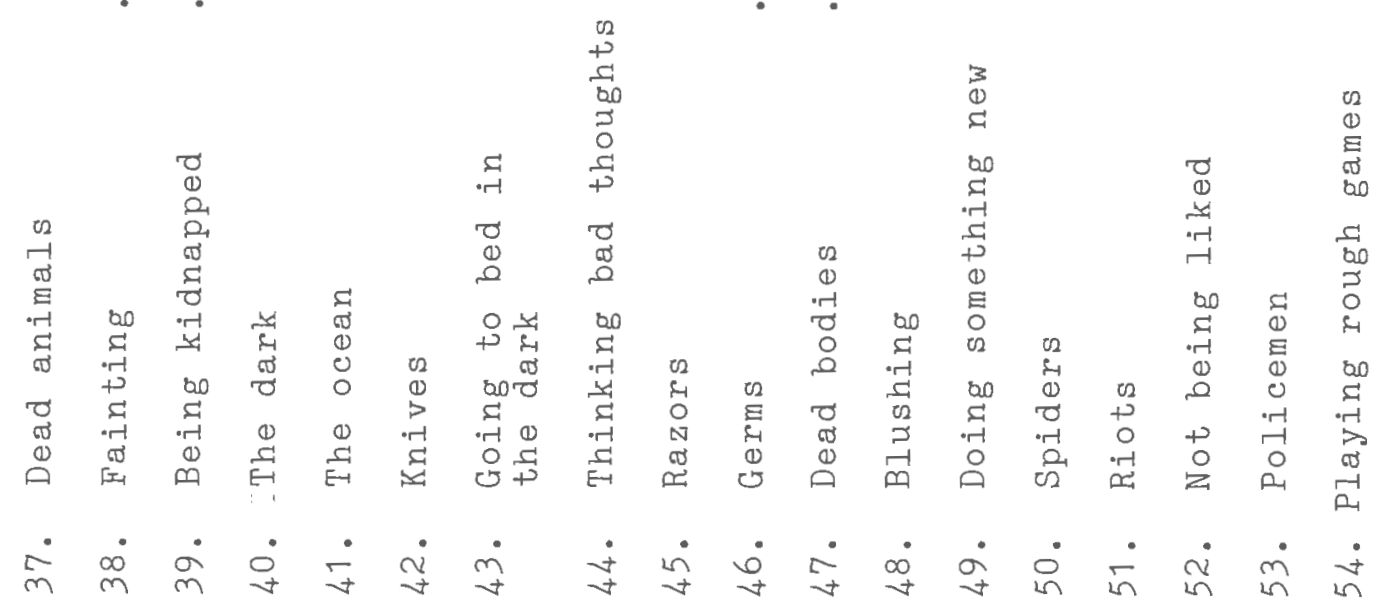




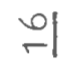

in

i

ty

m

N1

다

$\stackrel{1}{\circ}$

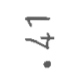

01

m

$\infty \quad \frac{n}{2}$

$\stackrel{+}{n}$

$-1$

01

in

$\rightarrow$ 강

mI

NI

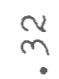

in

$-1$

$\stackrel{+}{m}$

$\stackrel{\infty}{0}$

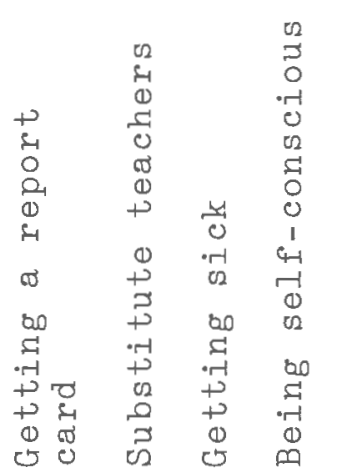



$\stackrel{5}{\square}$

$\stackrel{v}{n}$

in

$\stackrel{\circ}{n}$
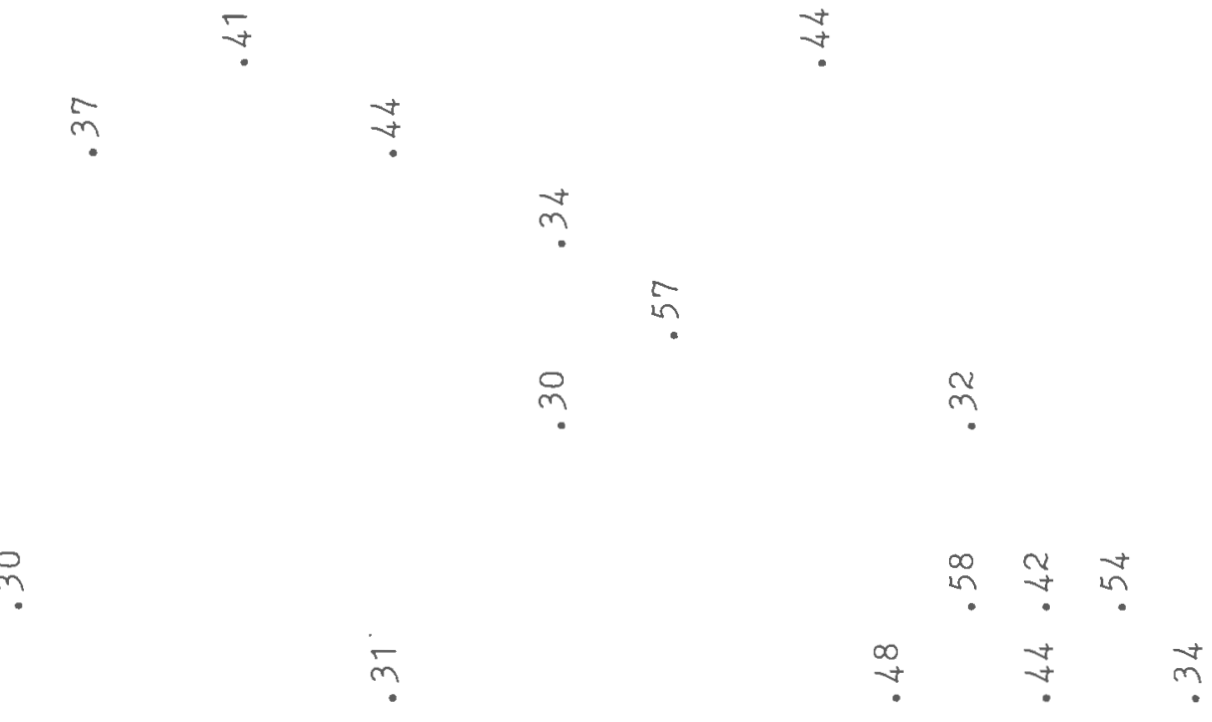

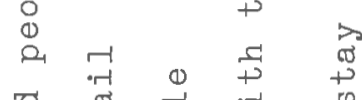

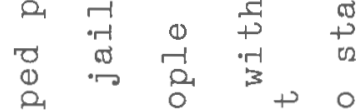

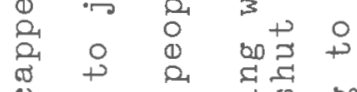

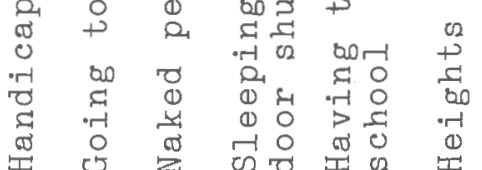

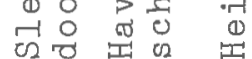

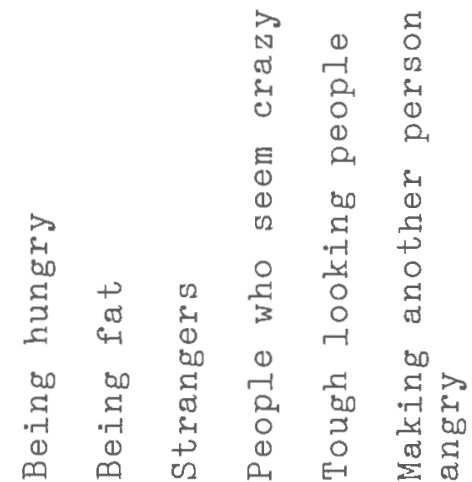

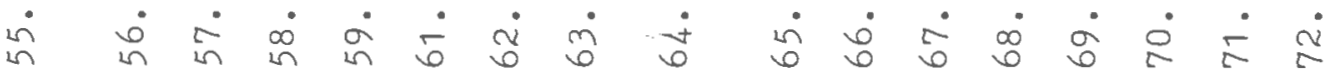


$\stackrel{6}{-1}$

n

가

$\stackrel{n}{n}$

$m$

ㄴ.

$\stackrel{ }{\bullet} \stackrel{+}{\bullet}$

디

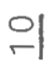

al m $\stackrel{n}{m}$

$\infty$ |

$-1$

!

$\stackrel{n}{m}$

-1

ก

$\stackrel{a}{m}$

$\hat{m}$

$\stackrel{\circ}{n}$

이

in

त $\stackrel{7}{\square}$

ml

N

$-1$

$\bar{m}$

$m$ m

$\stackrel{m}{?}$

2n

$\stackrel{0}{*}$

$\stackrel{\circ}{n}$

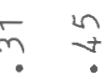


의

if

가

m

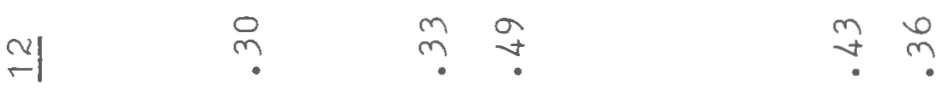

FI

의

or

$\infty 1$

-

ol

n

$+1$

$m$

$\stackrel{?}{?}$

m. in ?

$\stackrel{\infty}{\dddot{m}} \stackrel{\circ}{?}$

NI

$-1 \quad \stackrel{0}{0}$ in

$\stackrel{2}{+}$

in

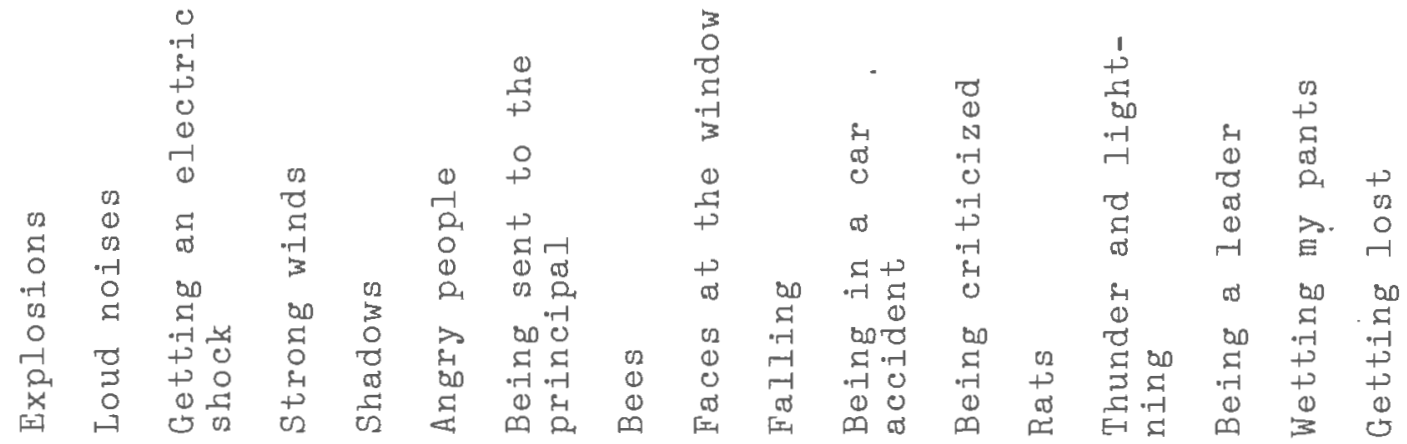

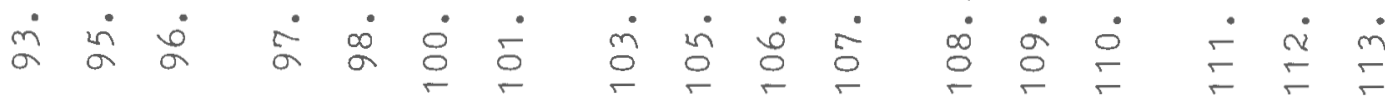


$\stackrel{1}{\leftarrow}$

in

가

m

vi in

-1

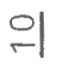

बr

$\infty$ I

-

01

니

$\stackrel{\circ}{\circ}$

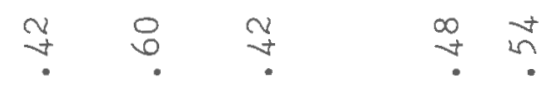

in

H

m

m

$\stackrel{\infty}{n}$

$\stackrel{\circ}{n}$

$\stackrel{\circ}{n}$

NI

$-1$

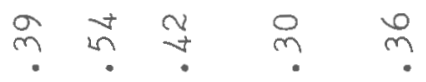

in

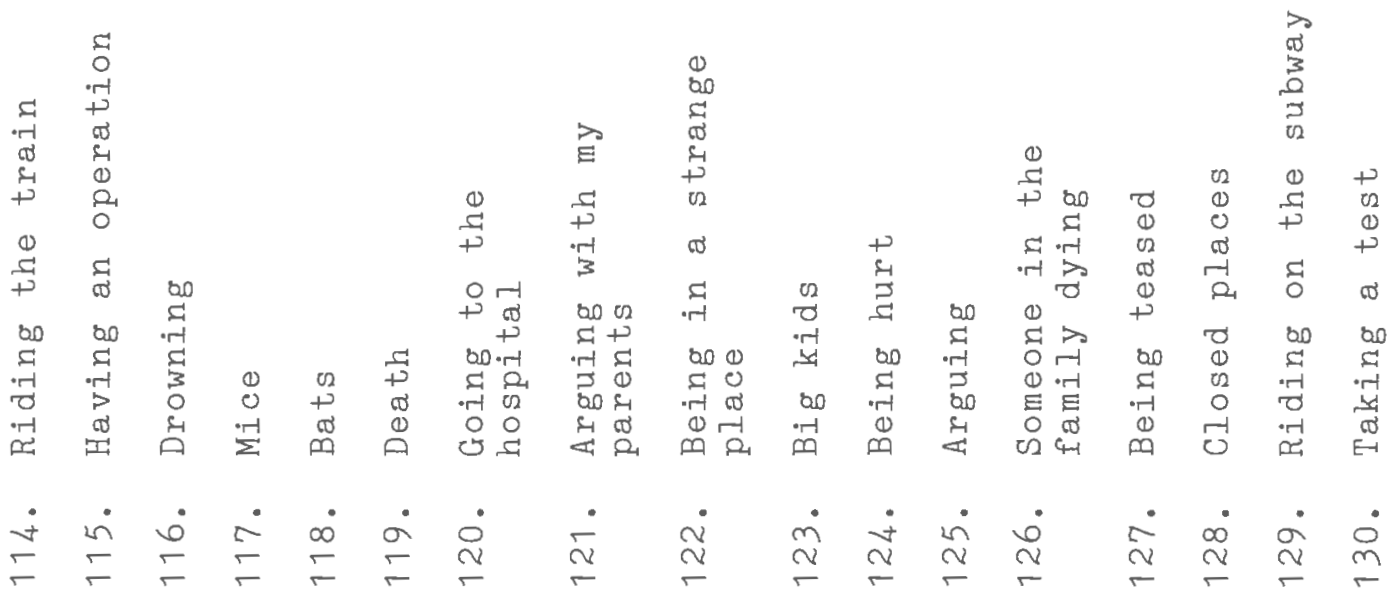




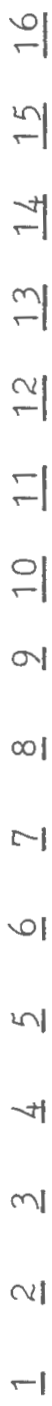

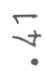

$\stackrel{m}{m}$



$\stackrel{q}{?}$

$\stackrel{m}{m} \stackrel{m}{n}$

$\stackrel{\circ}{n} \stackrel{\circ}{n}$

$\stackrel{\circ}{n}$

in $\stackrel{2 n}{?}$

$\stackrel{\pi}{m}$ in

$\stackrel{o}{m}$

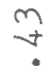

$\stackrel{n}{m} \stackrel{v}{m}$

$\stackrel{m}{ \pm} \stackrel{m}{m}$

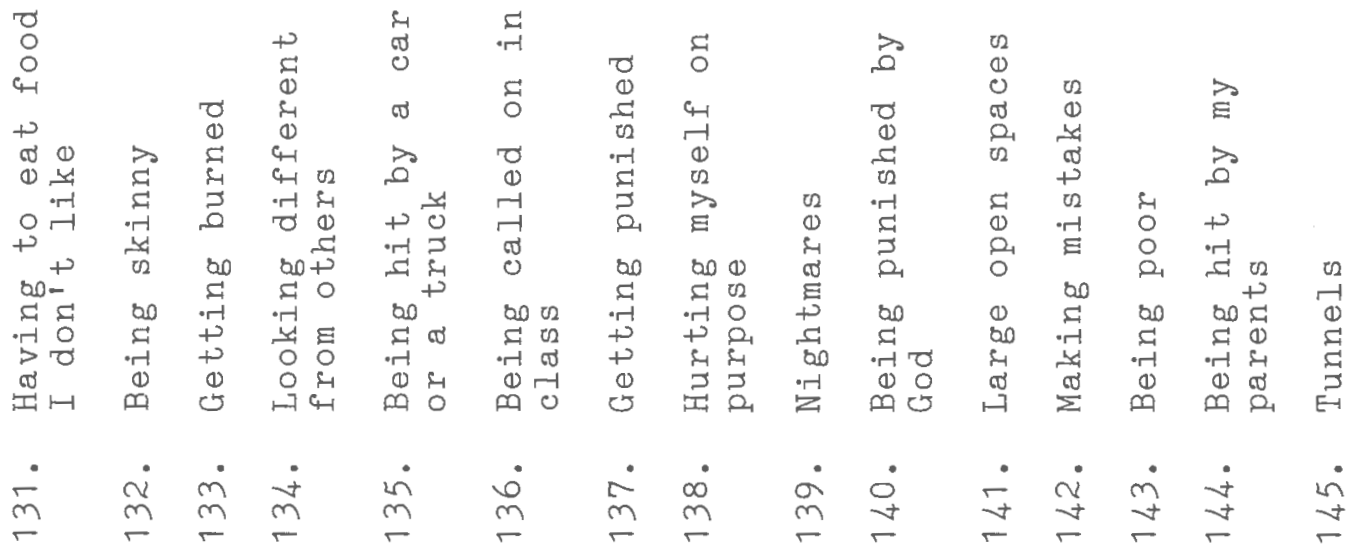




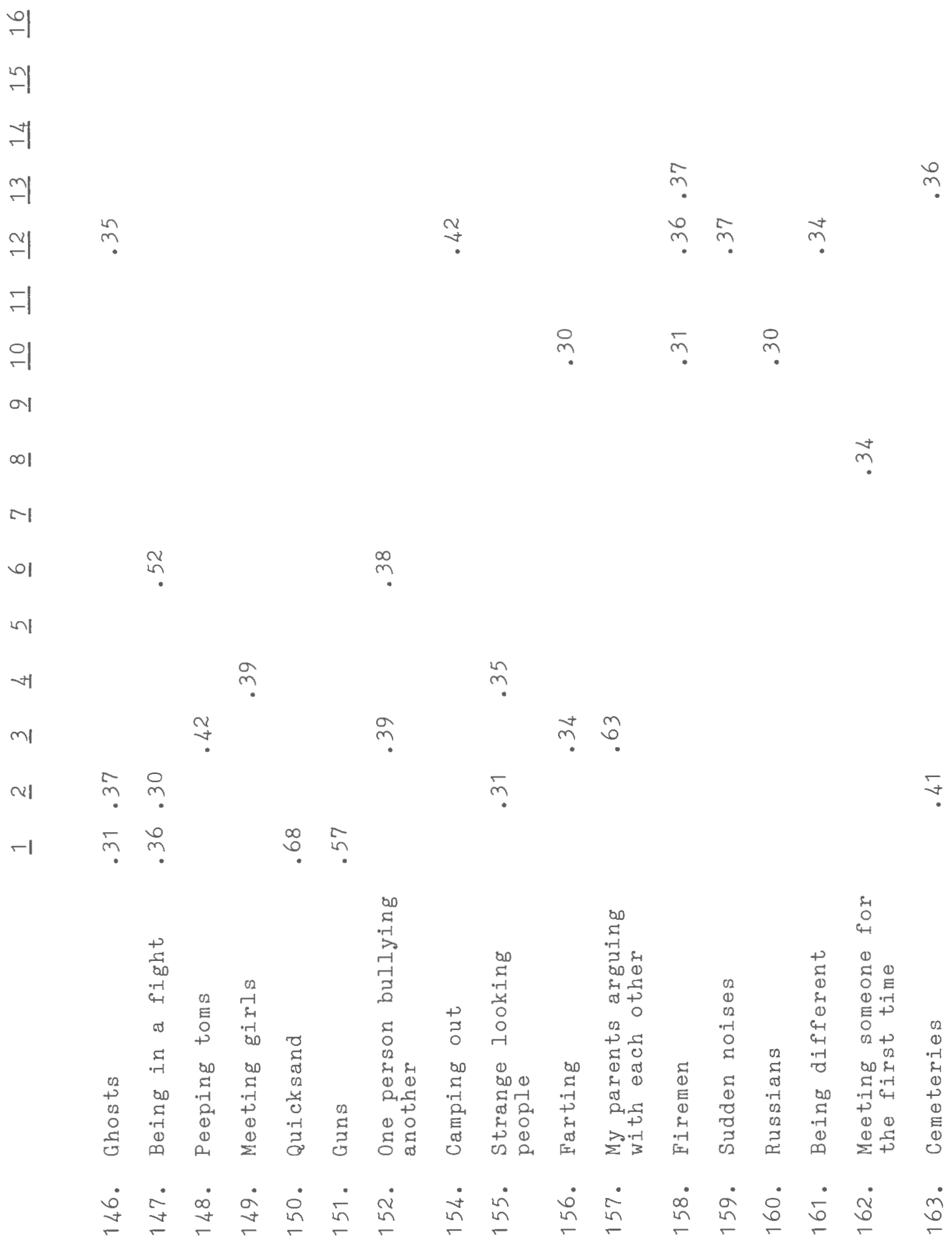




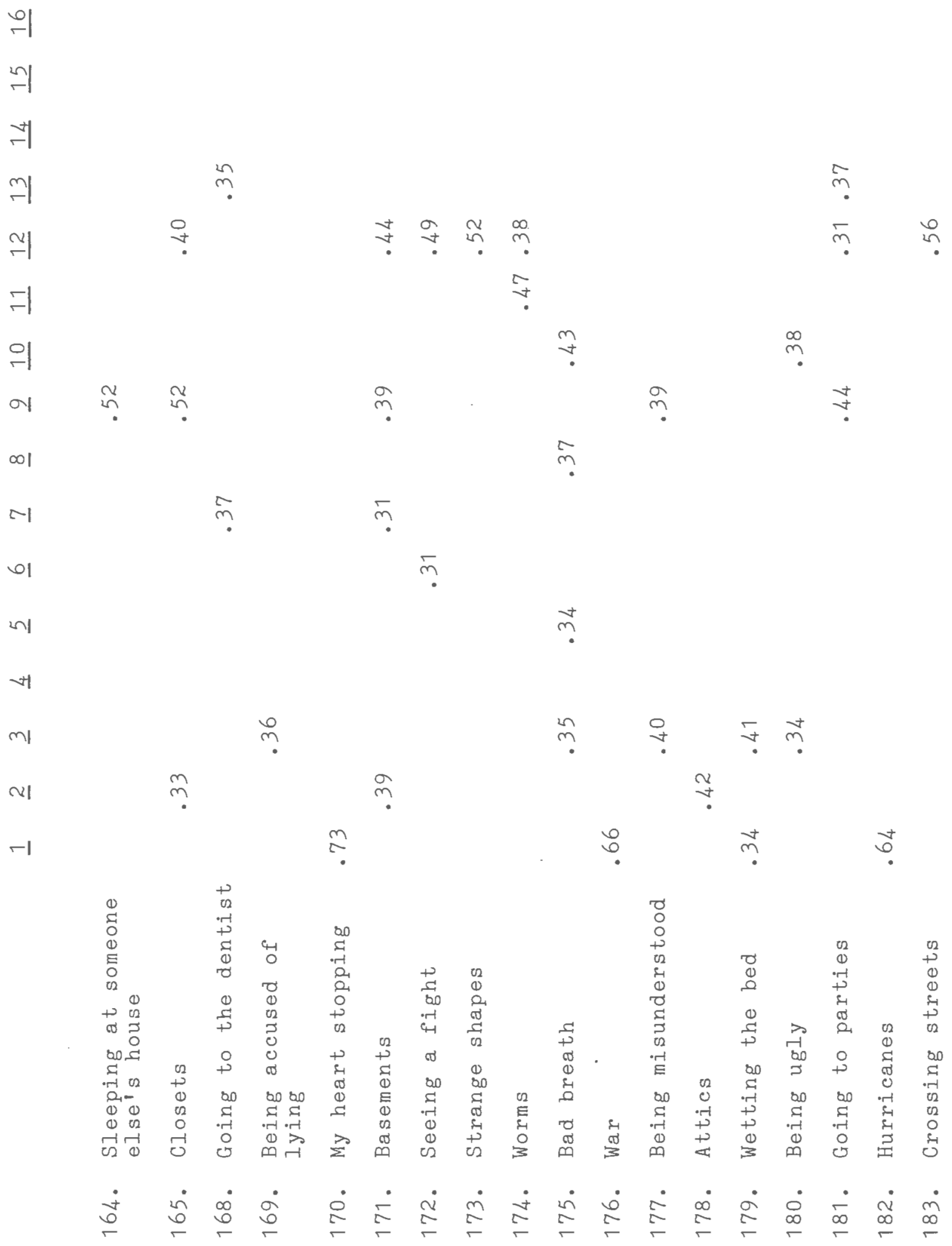




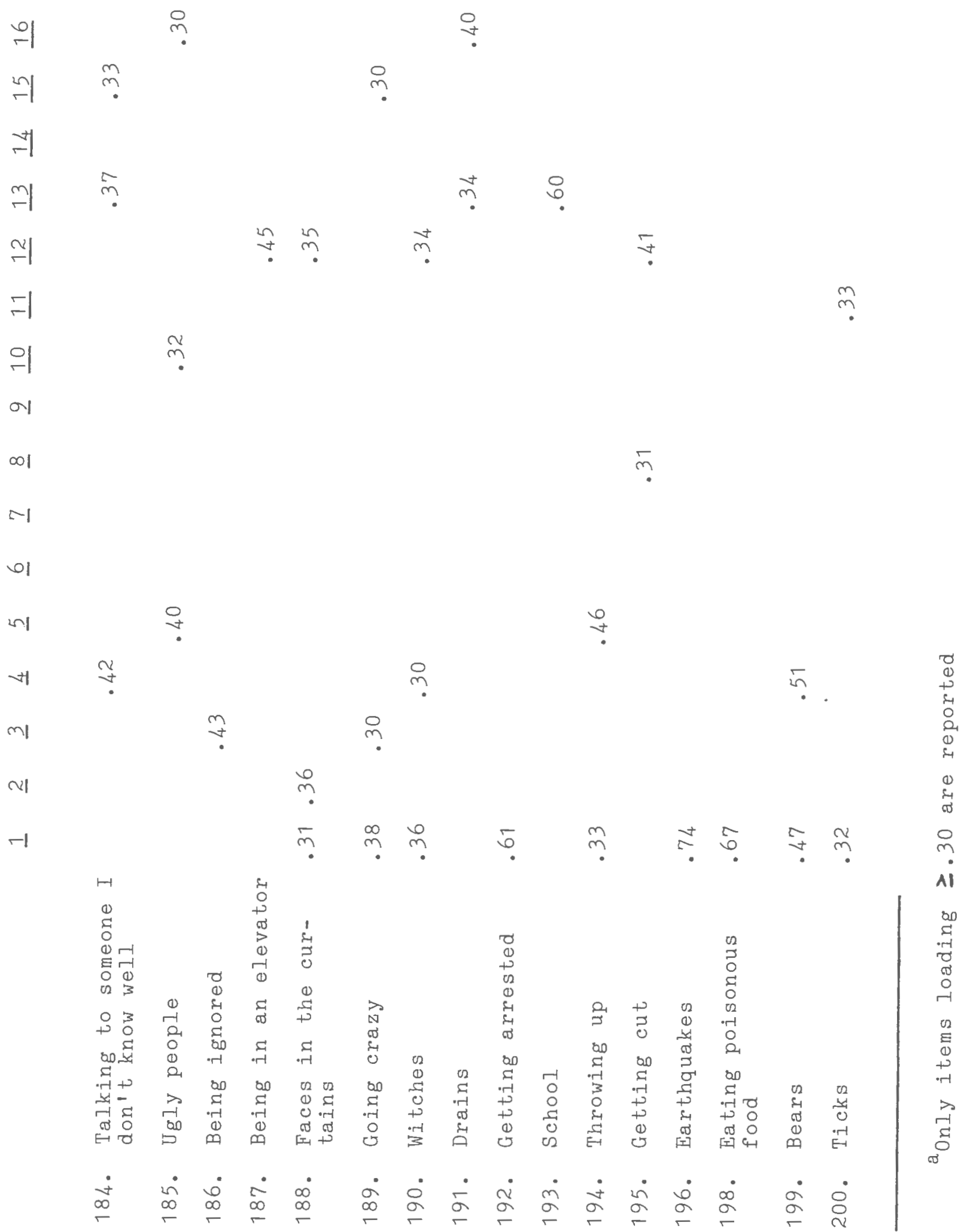


Appendix C

Item Elimination in Round One

1) 200 items. Principal Component Analysis produced two negative eigenvalues $(-.001,-.003)$. Six items with $\bar{X} \leq 1.11$ were eliminated:
4. Birds
$\overline{\mathrm{X}}=1.09$
18. Taking a bath or
1.09 shower
84. Going to gym
1.11
99. Mailmen
1.07
153. Talking on the telephone
1.07
197. Vacuum cleaners
1.10

2) 194 items. Principal Component Analysis produced one negative eigenvalue $(-.000)$. Eight items with $\bar{X} \leq 1.17$ were eliminated:
35. Dirt
$\overline{\mathrm{X}}=1.14$
60. Ants
1.17
83. Bathrooms
1.14
94. Escalators
1.16
102. A circus
1.12
104. Going shopping
1.14
166. Cats
1.15
167. Going to the movies
1.14

3) 186 items. Eliminated 43 low and complex items:
2. Being hit by a ball
$10 \mathrm{~W}$
5. Flying in a plane
low 


\begin{tabular}{|c|c|c|}
\hline 9. & Tigers & complex \\
\hline 22. & Poor grades & low \\
\hline 26. & Wolves & complex \\
\hline 31. & Leaving home & low \\
\hline 37. & Dead animals & low \\
\hline 41. & The ocean & Iow \\
\hline 45 & Razors & Iow \\
\hline 46. & Germs & low \\
\hline 47. & Dead bodies & low \\
\hline 57. & Getting sick & Iow \\
\hline 64. & Having to stay after school & Iow \\
\hline 66. & Tornados & complex \\
\hline 76. & Mystery movies & low \\
\hline 77. & Getting a shot & low \\
\hline 92. & Being left alone & low \\
\hline 97. & Strong winds & Iow \\
\hline 106. & Falling & Iow \\
\hline 110 & Thunder and lightning & low \\
\hline 118 & Bats & Iow \\
\hline 120 & Going to the hospital & complex \\
\hline 122 & Being in a strange place & Iow \\
\hline 128 & Closed places & low \\
\hline 138. & Hurting myself on purpose & Iow \\
\hline 140 & Being punished by God & complex \\
\hline 141. & Large open spaces & low \\
\hline
\end{tabular}




$\begin{array}{ll}\text { 144. Being hit by my parents } & \text { low } \\ \text { 146. Ghosts } & \text { low } \\ \text { 152. One person bullying another } & \text { low } \\ \text { 155. Strange looking people } & \text { low } \\ \text { 158. Firemen } & \text { low } \\ \text { 160. Russians. } & \text { low } \\ \text { 161. Being different } & \text { low } \\ \text { 171. Basements } & \text { low } \\ \text { 175. Bad breath } & \text { low } \\ \text { 177. Being misunderstood } & \text { low } \\ \text { 180. Being ugly } & \text { low } \\ \text { 188. Faces in the curtains } & \text { low } \\ 189 . & \text { Going crazy } \\ 190 . & \text { low } \\ 199 . & \text { Lears }\end{array}$

4) 143 items. Eliminated 27 low and complex items:

$\begin{array}{ll}\text { 23. Crowds } & \text { Iow } \\ \text { 24. Strange dogs } & \text { Iow } \\ \text { 42. Knives } & \text { low } \\ \text { 51. Riots } & \text { Iow } \\ \text { 53. Policemen } & \text { Iow } \\ \text { 58. Being self-conscious } & \text { Iow } \\ \text { 67. Being hungry } & \text { Iow } \\ \text { 72. Making another person angry } & \text { low } \\ \text { 74. Skunks } & \text { Iow } \\ \text { 80. Deep water } & \text { complex } \\ \text { 89. Going to the doctor } & \text { low }\end{array}$


95. Loud noises low

101. Being sent to the principal low

105. Faces at the window low

109. Rats low

113. Having an operation low

114. Riding the train complex

117. Mice low

129. Riding the subway low

154. Camping out low

159. Sudden noises low

163. Cemeteries low

169. Being accused of lying low

178. Attics low

194. Throwing up low

195. Getting cut low

200. Ticks low

5) 116 items. Eliminated 21 items with Varimax Rotated Factor Matrix Loading $<.600$ on the largest component, leaving 16 items on that component. The items eliminated were:
1. U.F.O.'s
Loading $=.443$

3. Snakes

8. Choking

12. Getting something in my eye

.330

15. Fire

.538

20. Being locked up

.594

27. Being adopted

.406

28. Being seen naked

.412 
29. My parents leaving me

.470

34. Blizzards

.432

36. Losing control

.435

38. Fainting

.527

81. Hell

88. The devil

.479

96. Getting an electric shock

.523

115. Having an operation

.466

119. Death

.570

126. Someone in the family dying

.592

133. Getting burned

.540

143. Being poor

151. Guns

6) 95 items. Eliminated 26 low and complex items:

$\begin{array}{ll}\text { 10. Feeling angry } & \text { low } \\ \text { 11. Swimming alone } & \text { low } \\ \text { 16. New teachers } & \text { low } \\ \text { 19. Going to the school nurse } & \text { low } \\ \text { 48. Blushing } & \text { low } \\ \text { 49. Doing something new } & \text { low } \\ \text { 50. Spiders } & \text { low } \\ \text { 62. Naked people } & \text { complex } \\ \text { 73. Sick people } & \text { low } \\ \text { 75. Roller coasters } & \text { complex } \\ \text { 86. Giving a report in class } & \text { low } \\ \text { 98. Shadows } & \text { low } \\ \text { 103. Bees } & \text { low } \\ \text { 108. Being criticized } & \text { low }\end{array}$




$\begin{array}{ll}\text { 111. Being a leader } & \text { low } \\ \text { 112. Wetting my pants } & \text { low } \\ \text { 131. Having to eat food I } & \text { low } \\ \text { don't like } & \text { low } \\ \text { 134. Looking different from } & \text { low } \\ \text { 136. Being called on in class } & \text { low } \\ \text { 145. Tunnels } & \text { low } \\ \text { 148. Peeping toms } & \text { low } \\ \text { 168. Going to the dentist } & \text { low } \\ \text { 173. Strange shapes } & \text { low } \\ \text { 179. Wetting the bed } & \text { low } \\ \text { 191. Drains low } & \end{array}$

7) 69 items. Eliminated the seventh component from the 69 item solution:

59. Handicapped people

90. Hospital smells

132. Being skinny

8) 66 items. One low item eliminated:

82. Leaving friends low

9) 65 items. One low item eliminated:

54. Playing rough games low

10) 64 items. One low item eliminated:

181. Going to parties low

11) 63 items. One complex item eliminated:
69. Strangers
complex

12) 62 items. Two low items eliminated:
100. Angry people
low
123. Big kids
low 
13) 60 items. One complex item eliminated:

165. Closets

complex

14) 59 items. 
Appendix D

\section{ROUND TWO}

FEAR EXPRESSION AND RESEARCH SURVEY

(F.E.A.R.S.)

The items you will find here are ones that children are sometimes afraid of. You are to circle the number that says how afraid you are of each item. Your choices are: $\frac{1-\text { not at all; }}{1-1}$ 2- alittle bit; 3 - some; 4 - much; 5 - very much. People are often afraid of different things and in different ways. Answer for yourself. There are no right or wrong answers. Your answers will not be shown to your teachers or to your parents. Please make sure you answer each item.

Before you begin, please fill in the spaces below.

Name

Date of Birth

Grade

Check: Boy _ Girl

Name of your school 


\begin{tabular}{c}
$\begin{array}{r}\text { not at a little } \\
\text { all bit some much much }\end{array}$ \\
\hline
\end{tabular}

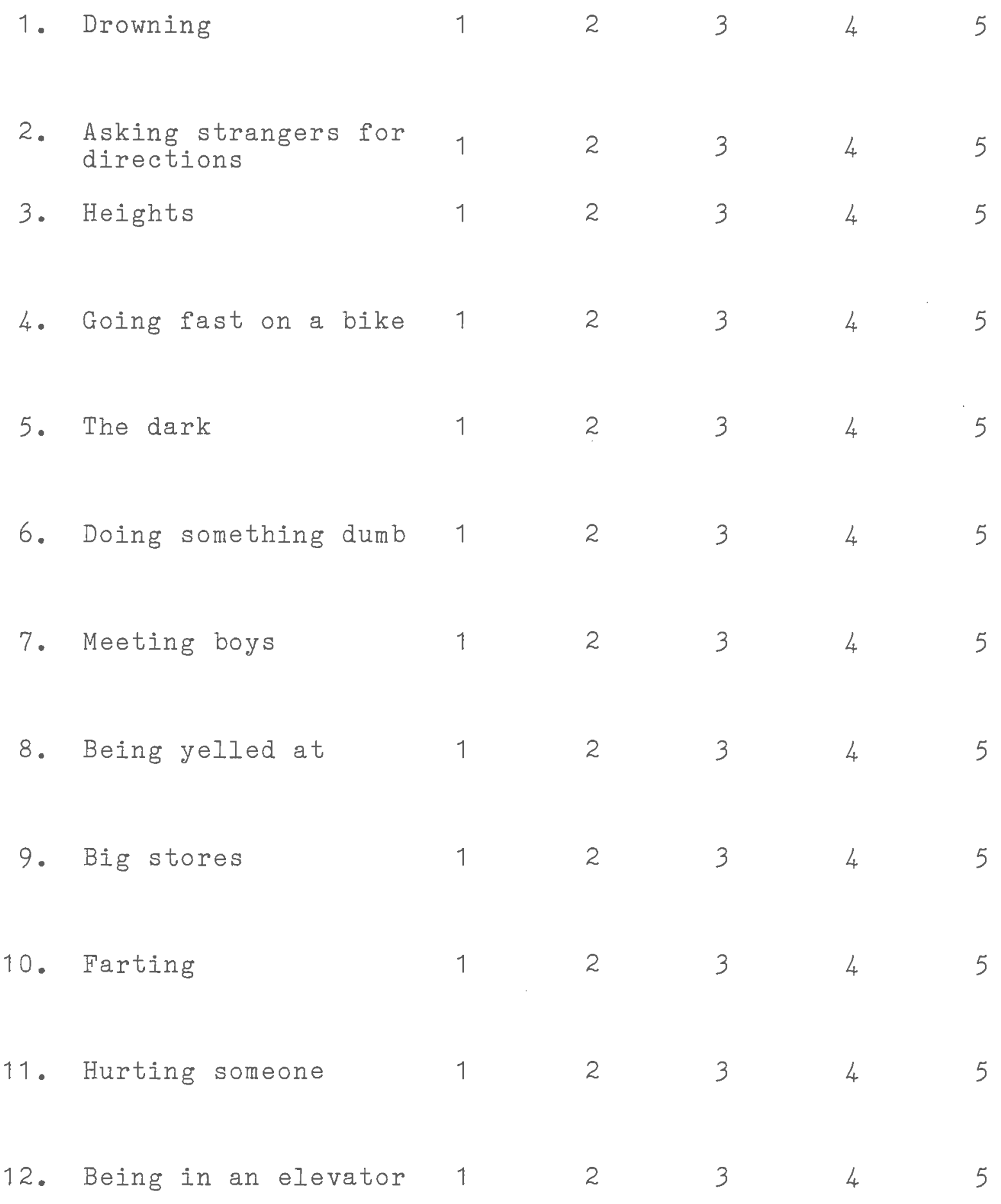




$$
\text { not at a little }
$$$$
\text { aII }
$$
bit

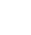

13. Getting punished

14. Seeing a fight

15. Making mistakes

16. Arguing with my parents

17. Spider webs

18. My heart stopping

19. Eating poisonous food 1

20. Meeting someone for the first time

21. Explosions

22. Scraping my knee

23. Taking a test

24. Climbing ladders

1

1

2

3

4

5

5

2

3

4

2

3

4

5

2

3

4

5

5

23

4

5

5



not at
a little al1 bit

25. Not being believed

2

3

4

5

26. Horror movies

1

2

3

4

5

27. Riding in a bus

1

2

3

4

5

28. Being hurt

1

2

3

4

5

29. Hurricanes

1

2

3

5

30. Being kidnapped

1

2

3

4

5

31. Talking to someone

I don't know well

1

2

3

5

32. Arguing with a teacher

1

2

3

4

5

33. Burping

1

2

3

4

5

34. Tough looking people 1

2

3

4

5

35. School

1

2

3

4

5

36. Nightmares

1

2

3

4

5 
not at a little

alI bit

some

much

very much

37. Substitute teachers 1

2

3

4

5

38. Going to parties

1

2

3

5

39. People who seem crazy 1

2

3

4

5

40. Moving to a new neighborhood

1

2

3

5

41. Tooth aches

1

2

3

4

5

42. My parents arguing with each other

1

2

3

4

5

43. Ugly people

1

2

3

4

5

44. Sleeping with the door shut

1

2

3

5

45. Arguing

1

2

3

4

5

46. Making new friends

1

2

3

4

5

47. Cutting my finger

1

2

3

4

5

48. Body odor

1

2

3

4

5 
not at a little

all

bit
2 card
49. Getting a report

$$
\text { cara }
$$

50. Arguing with a friend 1
51. Being attacked from behind

52. Failing a test

53. War

54. Going to a new school 1

55. Bridges

56. Looking foolish

57. Carnival rides

58. Sleeping at someone else's house

59. Graveyards

60. Worms

1

1

1

1

2

2

2

2

3

3

4

5

1

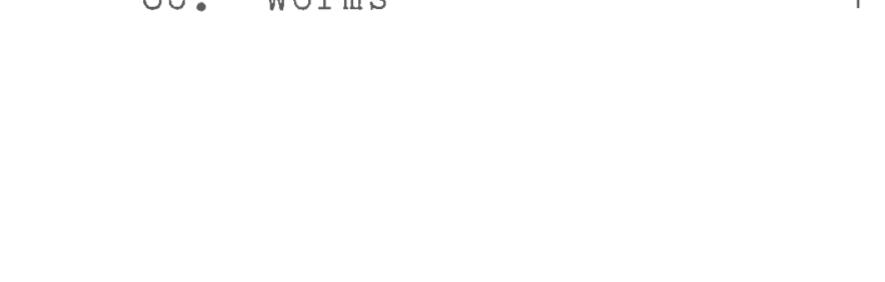


.

61. Thinking bad thoughts 1

2

3

4

5

62. Being in a car

1

2

3

5

63. Not being liked

1

2

3

5

64. Being fat

1

2

3

5

65. Earthquakes

1

2

3

5

66. Being ignored

1

2

3

5

67. Going to jail

1

2

3

5

68. Cancer

1

2

3

5

69. Sleeping with the
door shut

70. Meeting girls

1

2

3

5

71. A robber breaking into our house

1

2

3

4

5

72. Crossing streets

1

2

3

4 
not at

all

73. Blood

74. Haunted houses

75. Quicksand

76. Being teased

77. Riding in a car

78. Going to bed in the dark

1

2

2

2

2

79. Being hit by a car or a truck

80. Getting shot

1

81. Spooky stories

82. Bugs

83. Stupid people

84. Being in a fight
2

2

2

2

2

2

.

3

4

5 


\author{
Apperdix $E$
}

Item Elimination and Selection for

Rounds one and Two

1) 59 items. Eliminated the items from the last two components of Round One:

Rnd 1 Rnd 2

156. 10. Farting

142. 15. Making mistakes

130. 23. Taking a test

185. 43. Ugly people

17. 48. Body odor

55. 49. Getting a report card

164. 58. Sleeping at someone else's house

162. 20. Meeting someone for the first time

184. 31. Talking to someone I don't know well

193. 35. School

56. 37. Substitute teachers

149. 70. Meeting girls

2) 47 items. Dropped "Surprises" component items.

65. 3. Heights

187. 12. Being in an elevator

172. 14. Seeing a fight

87. 27. Riding in a bus

21. 55. Bridges

78. 57. Carnival rides

174. 60. Worms 
$\underline{\text { Rnd } 1}$ Rnd 2

183. 72. Crossing streets

85. 77. Riding in a car

7. 82. Bugs

3) 37 items. Dropped 6 items which were either complex or lower than desired or which had switched to another component:

$\begin{array}{rlll}\text { 33. } & \text { 7. } & \text { Meeting boys } & \text { switch } \\ \text { 44. } & 61 . & \text { Thinking bad thoughts } & \text { complex } \\ \text { 127. } & 76 . & \text { Being teased } & \text { complex } \\ \text { 30. } & \text { 73. } & \text { Blood } & \text { switch } \\ \text { 71. } & 34 . & \text { Tough looking people } & \text { below . } 500 \\ \text { 70. } & 39 . & \text { People who seem crazy } & \text { below . } 500\end{array}$

4) 31 items. Eliminated 5 items from the "Death" component to cut it down to 10 items.

116. 1. Drowning

176. 53. War

32. 68. Cancer

79. 71. A robber breaking into our house

182. 29. Hurricanes

5) 26 items. Eliminated 4 items which were not factorially invariant.

14. 11. Hurting someone

91. 25. Not being believed

157. 42. My parents arguing with each other

147. 84. Being in a fight

6) 22 items. Factorially invariant except for "Being in a car accident" (Round One solution). 
Attempted to rotate six components rather than four or five by putting back "Novelty" and "Surprise" components.

7) 44 items. Eliminated 7 items which stayed on "Surprises" component ( $\bar{X}$ too low), 6 items which were variant, and 1 complex item:

$\underline{\text { Rnd } 1} \underline{\text { Rnd } 2}$

$\begin{array}{ccll}\text { 21. } & \text { 55. } & \text { Bridges } & \text { Surprises } \\ \text { 65. } & \text { 3. } & \text { Heights } & \text { Surprises } \\ \text { 78. } & \text { 57. } & \text { Carnival rides } & \text { Surprises } \\ \text { 85. } & \text { 77. } & \text { Riding in a car } & \text { Surprises } \\ \text { 87. } & \text { 27. } & \text { Riding in a bus } & \text { Surprises } \\ \text { 183. } & \text { 72. } & \text { Crossing streets } & \text { Surprises } \\ \text { 187. } & \text { 12. } & \text { Being in an elevator } & \text { Surprises } \\ \text { 91. } & \text { 25. } & \text { Not being believed } & \text { variant } \\ \text { 149. } & \text { 70. } & \text { Meeting girls } & \text { variant } \\ \text { 185. } & \text { 43. } & \text { Ugly people } & \text { variant } \\ 30 . & 73 . & \text { Blood } & \text { variant } \\ 33 . & 7 . & \text { Meeting boys } & \text { variant } \\ 193 . & 35 . & \text { School } & \text { variant } \\ 156 . & 10 . & \text { Farting } & \text { complex }\end{array}$

Added:

139. 36. Nightmares

8) 31 items. Eliminated "Novelty" items and 1 complex item:

162. 20. Meeting someone for the first time Novelty

130. 23. Taking a test Novelty

184. 31. Talking to someone I don't know well Novelty

56. 37. Substitute teachers Novelty

127. 76. Being teased complex 
9) 26 items. Eliminated 2 complex items:

\section{Rnd 1 Rnd 2}

44. 61. Thinking bad thoughts

147. 84. Being in a fight

10) 24 items. Invariant except for 1 item ("Nightmares"). Added the 10 new items (out of 25) which loaded on the four components of the 24-item solution:

6. Doing something dumb

33. Burping

50. Arguing with a friend

52. Failing a test

26. Horror movies

59. Graveyards

74. Haunted houses

81. Spooky stories

8. Being yelled at

32. Arguing with a teacher

11) 34 items. 


$$
\begin{aligned}
& \text { Appendix } F \\
& \text { Unrotated Factor Matrix - Round One }
\end{aligned}
$$

\begin{tabular}{|c|c|c|c|c|}
\hline Getting shot & .672 & -.403 & -.013 & .114 \\
\hline Being kidnapped & .664 & -.366 & -.091 & .161 \\
\hline Going to jail & .752 & -.249 & .055 & .130 \\
\hline Explosions & .713 & -.178 & -.114 & -.126 \\
\hline Being in a car accident & .673 & -.276 & .001 & -.223 \\
\hline Being hit by a car or a truck & .712 & -.346 & -.137 & -.097 \\
\hline Quicksand & .702 & -.215 & -.111 & .147 \\
\hline My heart stopping & .664 & -.399 & -.192 & .017 \\
\hline Earthquakes & .670 & -.365 & -.107 & -.023 \\
\hline Eating poisonous food & .718 & -.269 & -.047 & .157 \\
\hline Body odor & .344 & .045 & .393 & .349 \\
\hline Looking foolish & .532 & .269 & .447 & .117 \\
\hline Not being liked & .455 & .138 & .517 & .187 \\
\hline Being fat & .527 & .172 & .377 & .200 \\
\hline People who seem crazy & .491 & .192 & .322 & .102 \\
\hline Being ignored & .544 & .396 & .183 & .130 \\
\hline Arguing with my parents & .609 & .212 & .162 & -.499 \\
\hline Being hurt & .587 & .283 & .037 & -.371 \\
\hline Arguing & .623 & .344 & -.021 & -.385 \\
\hline Getting punished & .625 & .286 & .114 & -.324 \\
\hline The dark & .452 & .528 & -.406 & .128 \\
\hline Going to bed in the dark & .397 & .491 & -.457 & .310 \\
\hline Sleeping with the door shut & .426 & .522 & -.385 & .251 \\
\hline Nightmares & .592 & .251 & -.332 & -.006 \\
\hline
\end{tabular}


Appendix $G$

Unrotated Factor Matrix - Round Two

\begin{tabular}{|c|c|c|c|c|}
\hline Getting shot & .725 & -.346 & .138 & .052 \\
\hline Being kidnapped & .700 & -.300 & .132 & -.065 \\
\hline Going to jail & .750 & -.314 & -.028 & .000 \\
\hline Explosions & .643 & -.148 & .070 & .210 \\
\hline Being in a car accident & .740 & -.160 & .054 & -.100 \\
\hline Being hit by a car or a truck & .774 & -.335 & .039 & -.048 \\
\hline Quicksand & .722 & -.158 & -.014 & -.041 \\
\hline My heart stopping & .642 & -.482 & .137 & .017 \\
\hline Earthquakes & .649 & -.309 & .047 & -.080 \\
\hline Eating poisonous food & .659 & -.422 & .127 & .055 \\
\hline Body odor & .462 & .224 & -.221 & -.192 \\
\hline Looking foolish & .480 & .442 & -.243 & -.397 \\
\hline Not being liked & .549 & .337 & -.431 & -.164 \\
\hline Being fat & .551 & .098 & -.316 & -.395 \\
\hline People who seem crazy & .436 & .284 & -.363 & .078 \\
\hline Being ignored & .555 & .330 & -.298 & -.143 \\
\hline Arguing with my parents & .413 & .399 & -.091 & \\
\hline Being hurt & .603 & .153 & -.039 & .232 \\
\hline Arguing & .539 & .382 & -.158 & \\
\hline Getting punished & .438 & .286 & -.158 & .532 \\
\hline The dark & .300 & .540 & .581 & -.036 \\
\hline Going to bed in the dark & .304 & .389 & .647 & -.127 \\
\hline Sleeping with the door shut & .348 & .502 & .530 & -.2 \\
\hline Nightmares & .491 & .337 & .274 & \\
\hline
\end{tabular}

